FESIOE

Fundación Emilio Soldevilla de la Investigación y Desarrollo de la Economía de la Empresa

\section{Management Letters / Cuadernos de Gestión}

\author{
journal homepage: http://www.ehu.eus/cuadernosdegestion/revista/es/
}

ISSN: 1131-6837 / e-ISSN: 1988-2157

\title{
Discovering prominent themes of the application of eye tracking technology in marketing research
}

\section{Descubriendo temas destacados de la aplicación de la tecnología de eye tracking en la investigación de marketing}

\author{
Francisco Muñoz-Leiva*, María Eugenia Rodríguez-Lópeza , Bárbara García-Martíb \\ a Faculty of Education, Economy and Technology of Ceuta. Dpt. Marketing and Market Research, University of Granada. C/. Cortadura del Valle s.n. CP: 51001 Ceuta, \\ Spain. - eugeniarodriguez@ugr.es - https://orcid.org/0000-0001-7882-5991 \\ ${ }^{b}$ Faculty of Education, Economy and Technology of Ceuta. University of Granada. C/ Cortadura del Vall, s/n, 51001, Ceuta, Spain. - barbara97@correo.ugr.es - \\ https://orcid.org/0000-0002-8480-4086
}

* Corresponding author: Department of Marketing and Market Research, Campus Universitario La Cartuja, s/n. Universidad de Granada, Sport and Health University Research Institute (iMUDS). C/. Menéndez Pelayo, 32, 18016, Granada, Spain. - franml@ugr.es - https://orcid.org/0000-0002-4996-7525

\section{A R T I C L E I N F O}

Received 04 June 2021

Accepted 09 October 2021

Available online 10 February 2022

DOI: $10.5295 / \mathrm{cdg} .211516 \mathrm{fm}$

JEL: M31, C00

\section{A B S T R A C T}

This study shows the main results of a bibliometric analysis of academic research that has applied eye tracking technology in the marketing discipline, drawing from 923 documents extracted from the WoS bibliographic database. The aims of the study are to (i) identify the structure of the relationships between past and current research topics, (ii) provide a longitudinal perspective on eye tracking as a research tool for academics, covering the period 1992-2020, and (iii) identify emerging research trends for the future.

Among other results, we find that the eye tracking methodology has been applied in marketing research particularly over the last decade due to scholarly interest in studying the visual attention of consumers and users in behavioral studies. More broadly, over the last 30 years, there are five major thematic areas identified: (a) brand-attention-modeling, (b) eye tracking-movements-communication, (c) web-online, (d) HCI-gaze-perception and (e) choice-labeling. The work is the first to identify the structure of the relationships between past and current research topics, and to predict future research trends in the marketing scholarship applying eye tracking as a research tool. Some limitations and potential future research themes are discussed at the end of the paper.

Keywords: Eye Tracking; Marketing; Web of Science; SciMAT; Bibliometric Map; Strategic Diagram; Thematic Network.

\section{R E S U M E N}

El presente estudio presenta los principales resultados de un análisis bibliométrico de la investigación académica que ha aplicado la tecnología de seguimiento ocular (eye tracking) en la disciplina del marketing, a partir de 923 documentos extraídos de la base de datos bibliográfica WoS. Los objetivos del estudio son (i) identificar la estructura de las relaciones entre los temas de investigación pasados y actuales, (ii) proporcionar una perspectiva longitudinal sobre el eye tracking como herramienta de investigación usada por los académicos, cubriendo el período 1992-2020, e (iii) identificar las tendencias de investigación emergentes para el futuro.

Entre otros resultados, encontramos que la metodología de eye tracking se ha aplicado en la investigación de marketing especialmente en la última década debido al interés por estudiar la atención visual de los consumidores y usuarios en los estudios de comportamiento. En términos más generales, en los últimos 30 años se han identificado cinco grandes áreas temáticas: (a) modelización-marca-atención, (b) seguimiento ocular-movimientos-comunicación, (c) web-online, (d) HCI-mirada-percepción y (e) elección-etiquetado.

El trabajo es el primero en identificar la estructura de las relaciones entre los temas de investigación pasados y actuales, $\mathrm{y}$ en predecir las futuras tendencias de investigación en los estudios de marketing que aplican eye tracking como herramienta de investigación. Al final del trabajo se discuten algunas limitaciones y posibles temas de investigación futura. Palabras clave: Eye Tracking; Marketing; Web of Science; SciMAT; Mapa Bibliométrico; Diagrama Estratégico; Red Temática. 


\section{INTRODUCTION}

Eye tracking is a "technique whereby an individual's eye movements are measured so that the researcher knows both where a person is looking at any given time and the sequence in which the person's eyes are shifting from one location to another" (Poole and Ball 2006); for example, when navigating on a website. The first eye tracking device was created in 1908 by Edmund Huey. This system consisted of a sort of contact lens with an opening that exposed the subject's iris, rendering it possible to trace their eye movements when reading. In the 1930s, Thomas Buswell developed another mechanism, a photographic device that reflected beams of light from the cornea and recorded the subjects' reactions on a moving film record (Flir 2016). In 1948, Hartridge and Thompson developed the first head-mounted eye tracking device. But it was not until the 1970s that the technology necessary for monitoring and using eye tracking data was developed, with the advent of mini-computers (Joseph and Murugesh 2020). At that time, psychologists were concerned with cognitive issues such as learning, memory, workload, and attention.

A review of the extant eye tracking tools reveals highly diverse examples (even bionic lenses that obtain extremely accurate data). In general, the most commonly-used eye tracking methods tend to be special glasses and cameras mounted on monitors or laptops, or head-mounted devices (helmets or caps, for instance). A more recently-developed alternative is the virtual reality (VR) eye tracker (Clay et al. 2019).

This technology is developed from the "eye-mind" premise proposed by Just and Carpenter (1980), and it is used to deepen our understanding of individuals' visual perception (Lai et al. 2013). Thanks to this technology, different types of eye movements have been described that are associated with intervals of effective vs. ineffective vision, with researchers reaching a consensus about the relationship between eye movements and attention.

The eye tracking methodology has been used in academic research for more than six decades and has been applied in an extremely diverse range of scientific areas, from psychological and medical diagnosis to studies on the usability of interactive applications and advertising effectiveness. For example, from a biological point of view, eye tracking has served to analyze ocular-following responses and thus explain communication behaviors in babies (Senju and Cesibra 2008).

Given the multidisciplinary range of applications of eye tracking as a research method, coupled with the autonomy of eye tracking as a technological discipline in its own right, with its own value and trajectory, it is commonly used in studies dealing with mental illnesses, for example, which are published in journals from areas such as the technological sciences (Senju et al. 2009). Similarly, there are studies that use eye tracking technology to investigate aspects of marketing, for instance, to analyze the effect of the color used in website design on user trust or satisfaction, which pertains to the areas of psychology and computer science (Cyr et al. 2010). Studies involving the eye tracking methodology that concern marketing from several research areas began to be developed in the 1990s-a focus attributed to, among other aspects, the fact that advances in scholarly under- standing of markets and consumer behavior are closely related to knowledge of consumer psychology, of the development of technologies, and of the technologies that can be implemented as methodological research tools.

From the point of view of marketing, the last few decades have witnessed several hundred studies featuring eye tracking as a research tool, which provide definitive findings in the realm of commercial communication, such as which elements of a print advertisement generate the most attention (Pieter and Wedel 2004) and which positions on the shelves of a retail establishment optimize consumer evaluation of brands and attract greater attention from buyers (Chandon et al. 2009). Other results have identified certain online user behaviors (Cyr et al. 2009). This wealth of scholarship points to the need to organize all the existing information on eye tracking in marketing research, and bibliometrics is a highly appropriate technique for this purpose as it uses a variety of precise quantitative measures on a consistent set of bibliographic data.

However, to date, only two studies have been identified that address the study of eye tracking methodology from a bibliometric perspective. The first is an analysis of the evolution of eye tracking technology applied to the field of cartography and map-reading (Wang et al. 2016); and the second focuses on identifying emerging issues in VR applications, "eye tracking" being among the most frequently-used terms (Zeng et al. 2018).

In light of the above considerations, a bibliometric study is required that captures the significant volume of scientific information generated around eye tracking in marketing during the last several decades, in pursuit of the following objectives: (1) to determine the scientific output dealing with eye tracking in marketing over the timeframe under study, (2) to identify the most productive authors and journals in the field, (3) to identify the main themes associated with the application of eye tracking, and their interrelationships, and (4) to analyze the evolution of the research topics over the years. Taking this bibliometric approach, it is possible to organize existing scientific information, forecast future research trends, and offer interesting recommendations for potential new academic and professional studies based on the bibliometric research methodology.

Against this backdrop, the present paper is structured thus: following this introduction, Section 2 provides a theoretical review of eye tracking, how it operates, and its functionalities, including the application of this technology in research, in general, and in marketing, in particular. This section also identifies the bibliometric studies on eye tracking that have been conducted to date. Section 3 presents the stages of the methodology followed in the present study, detailing: the bibliographic information-database selected, the periods under study, the evolution of the publication of eye tracking research, and the bibliometric analysis procedure carried out using SciMAT software. Section 4 presents the results of the performance analysis of authors and journals and of the co-word analysis of the research topics by periods, providing a longitudinal perspective. Section 5 sets out the main conclusions that will shed light on future research that may build on the findings of our bibliometric analysis. It is expected that the present work will serve as a guide to researchers and academics in their future research through the use of eye tracking or bibliometric studies. 


\section{THEORETICAL FRAMEWORK}

\subsection{Eye tracking technology procedure}

Using eye tracking methodology, researchers are able to address questions regarding where an individual fixes their gaze when reading, by tracing their eye movements-for example, whether they visually absorb the entire line of the text from start to finish, where in the text they seek relevant information, or whether their visual attention is attracted more by graphics than images. Such questions form the raison dêtre of the process of tracking eye movement.

Therefore, eye movements comprise mainly a sequence of fixations and saccades. Fixations are discrete periods of relative immobility of the eye while visual information is extracted-that is, they correspond to moments of attention to the stimulus (Rayner 1998). Saccades are rapid "jumps" between fixation points that enable individuals to fix an object with foveal vision; vision is therefore effectively suppressed during saccades. When carefully observing an object, a person performs many fixations (and saccades) to inspect it in detail and extract all the relevant information. This brain activity, although ostensibly very simple, is quite complex, as it involves a series of physical-chemical processes that require the activation of many areas of the brain and several functions to be performed.

Regarding the eye tracking procedure itself, this is based on a precise and complex process of synchronization or calibration that the researcher makes between an estimation of the individual's gaze position and the device itself and its software (Hassan and Herrero 2007). The interpretation of the data recorded in the system is carried out using data analytics software (such as BeGaze, Tobii Studio, Tobbi ProLab, or Ogama) that provides the researcher with graphs in the form of heatmaps and gaze patterns or so-called scanpaths, videos showing the total or partial visual trajectory followed by the user, and quantitative summary statistics, as well as the complete database that can be analyzed in other programs or programming languages (such as R or MatLab).

Thus, the graphical representations or resulting interpretive images - such as the saccadic route (scanpath) or heat maps (see Figure 1) - render a better qualitative understanding of the visual behaviors relating to the target stimulus, such as a computer screen, a website, an image, a video, an advertisement, an electronic document, a supermarket shelf, or a billboard, for instance (Drusch et al. 2014; Gascó 2020).
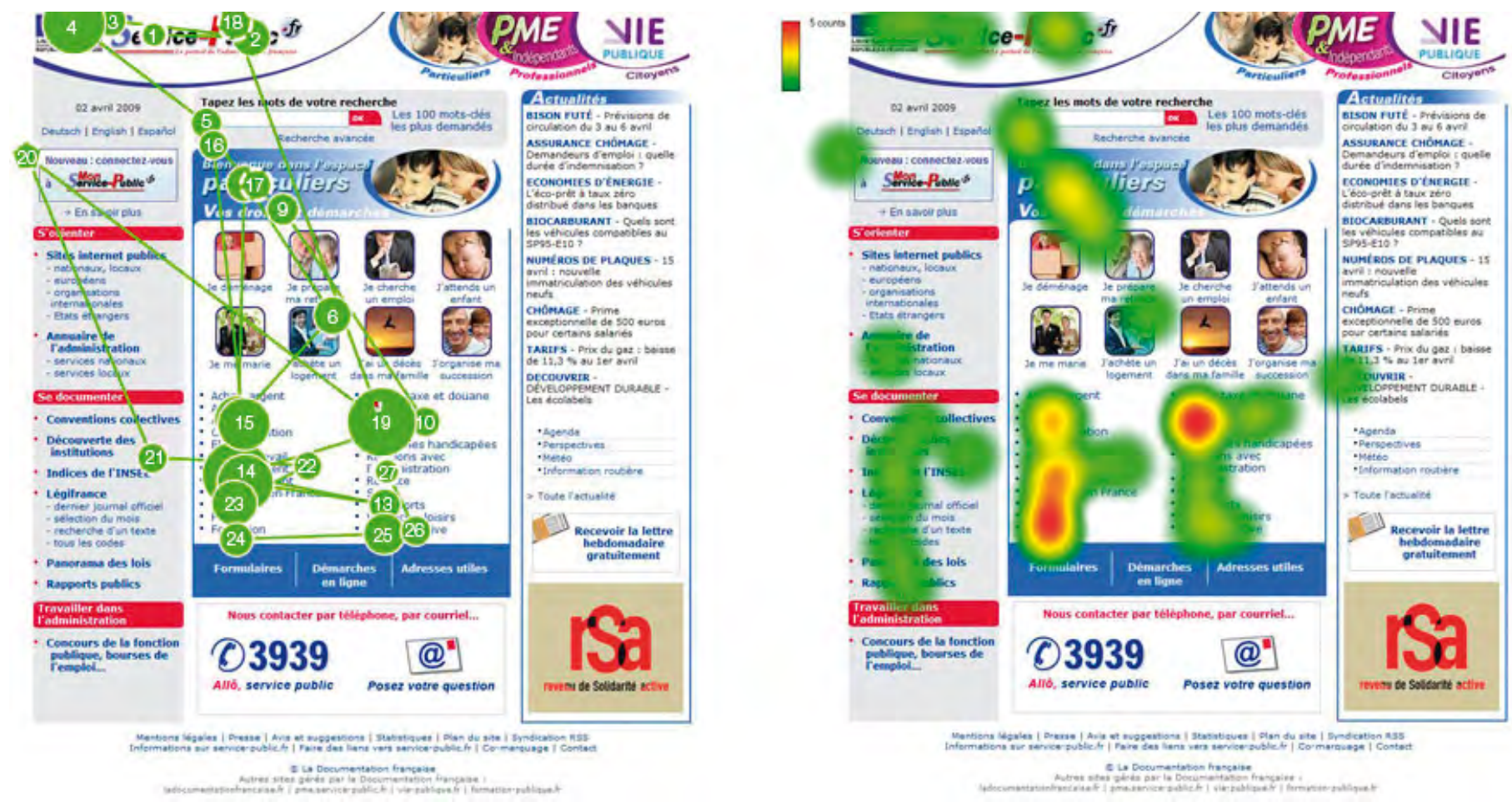

Figure 1

An individual's gaze plot (left) and a heatmap (right)

Source: Drusch et al. (2014).

\subsection{The role of eye tracking in marketing research}

It was not until the 1990s that eye tracking began to be employed as a tool for researching consumer behavior-thanks, in part, to the advances made in this and other technologies that made its study possible (Hassan and Herrero 2007). From 2000 onward, the most popular studies were those related to $\mathrm{HCI}$, which were primarily concerned with recording gaze direction and gaze patterns during web search (van der Lans et al. 2012). But the many possibilities offered by this technology have contributed to expanding its application across all four pillars of strategic marketing: product, price, place, and promotion. Among its benefits in the marketing context: 
- At the point of sale, it helps improve the position and presentation of the products on the shelves, increasing their visual prominence, and it can contribute to the study of the allocation of shelf space in relation to the use of slotting fees $(\mathrm{Mu}-$ ñoz-Leiva et al. 2021).

- In the study of online store design (Romano-Bergstrom and Schall 2014) or website usability (Matthews et al. 2020), this technology identifies the areas of the website most observed by the user vs. the "dead zones". Thus, companies are able to design their websites, which can determine the effect of the content on their clients, and they can identify feelings such as anxiety or frustration by studying the behavior and size of the pupils, thereby improving user perceived value (ibid.).

- This technology can support marketing efforts by helping to attract traffic to websites or landing pages (Ortiz 2020).

- It can contribute to achieving striking packaging design (Rytewiki 2019).

- Analysis of advertising effectiveness in offline or online contexts often makes use of eye tracking technology in relation to various determining factors of e-commerce that help increase online sales. These include banner placement, the location of information, and the use of certain colors on-screen (Hernández-Méndez and Muñoz-Leiva 2015 [airline banners]; Espigares-Jurado et al. 2020 [hotel websites]).

- Education has also been linked to the marketing area. For example, Juárez et al. (2019) discover an efficient method for the design of educational toys that helps increase sales

\subsection{Antecedents of research using eye tracking}

Eye tracking as a research tool is more accessible than ever and is growing in popularity among researchers from a whole host of disciplines such as (Holmqvist et al. 2011): usability analysts, sports scientists, cognitive psychologists, reading researchers, psycholinguists, neurophysiologists, electrical engineers, to name just a few, who employ gaze-tracking to test certain hypotheses. Other areas interested in this technology include marketing, artificial intelligence sciences, computer science, biology, and, more recently, business and economics.

According to a query processed in the Web of Science (WoS) database based on the words "eye tracking", "eye-tracking", or "eyetracking", a total of 19,643 academic papers were retrieved up to and including 2020. Specifically, scholarly interest in ocular fixation, visual attention, attention in reading-related tasks, or click behavior on the Internet, studied using eye tracking technology, has witnessed constant growth and has reached multiple research areas including (see Figure 2): Computer Science (accounting for $37.1 \%$ of total articles in the WoS database), Psychology (34.1\%), Behavioral Sciences (32.2\%), Engineering (28.9\%), Ophthalmology (26.2\%), Neurosciences/Neurology (24.0\%), Instruments/Instrumentation (13.5\%), or Communication $(11.2 \%)$.

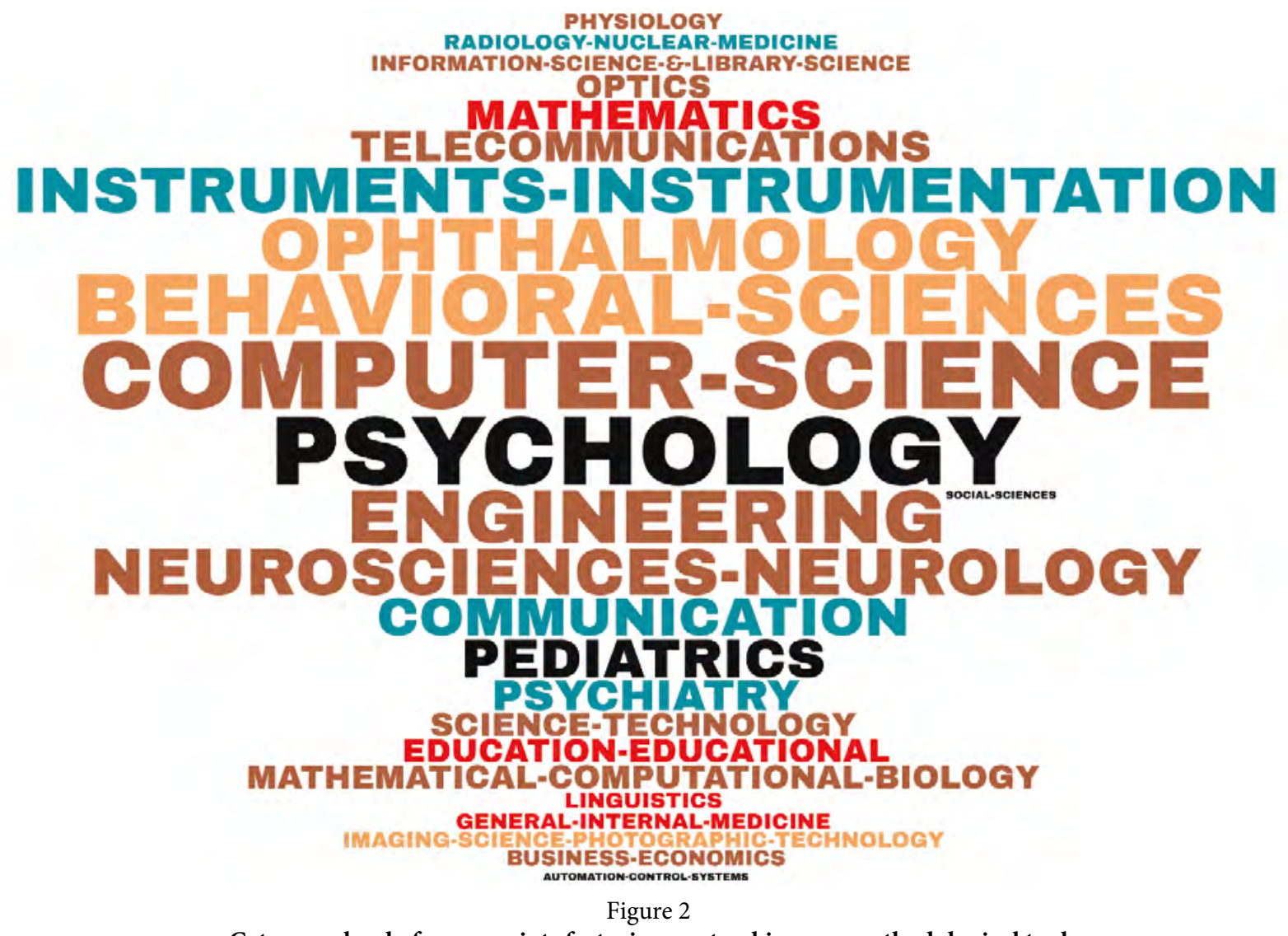

Category cloud of manuscripts featuring eye tracking as a methodological tool

Source: Own elaboration based on WoS data. 
The Computer Science category accounts for the largest number of studies, which have focused on analyzing eye movement and web-search efficiency with the help of this methodology. Among other authors, Van Der Lans et al. (2012) present a model that may serve to identify the paths (latent attention processes) of people searching for targets in visually-complex contexts, such as the Internet. Their model recognizes the spatial nature of eye movements and represents two latent attention states - a "localization" state and an "identification" state- between which people may switch over time (ibid.).

Psychology is the next-largest area of research that collects a significant amount of data related to this topic, followed by Behavioral Science (which is strongly linked to the marketing discipline), whose theoretical and practical principles have traditionally drawn on many concepts from the field of psychology (such as social and experimental psychology). Also common are studies that use eye tracking to analyze education- and psychiatry-related themes, addressing issues such as the visual-search behaviors of people with autism-spectrum disorder (ASD) (Dalton et al. 2007). Ophthalmology is another area linked to eye tracking that is concerned with analyzing intra-retinal morphological changes via clinical trials, for instance (Bolz et al. 2010).

\subsection{Bibliometric studies and their application to the eye tracking context}

Bibliometrics uses a wide range of techniques including author and document co-citation analysis, co-word analysis, and textual analysis (Glanzel 2015), using multivariate methods (see next subsection). In document co-citation analyses, the seminal documents with the most impact in a given research field are identified, and the matrix of co-citation frequencies between document pairs is analyzed (Small 1973). Callon et al. (1995) identified two main groups of bibliometric measures, namely those pertaining to productivity and relatedness. Productivity values measure scientific activity based on statistics and document characteristics, such as authors, citations, and sources, regardless of whether or not there is a relationship between them. In contrast, relatedness values are captured by bibliometric measures that do take into account similarities that may exist between articles.

The units of measurement generally selected for such analyses are journal articles, as the academic community acknowledges these publications to be the most advanced and up-to-date knowledge sources. They are also widely used in literature reviews in the marketing (and, more generally, management) field (e.g., Leone et al. 2012). In particular, keywords are the terms that characterize a study's main ideas and indicate the research trend that the authors are following (Garfield 1990). Co-occurrence or "co-word analysis" is relational (Callon et al. 1995) as it measures the joint instance of keywords extracted from each document, from which matrices of co-occurrences are constructed and similarity measures calculated. Co-word analysis is one of the most suitable methods for discovering trends and emerging issues in a given scientific field (see the co-word analysis procedure in the next section).

Despite the numerous functionalities and applications of eye tracking in various fields of study, an extensive review of the liter- ature discovered only three bibliometric studies linking the topic under study with the use of eye tracking. The first bibliometric study analyzed eye tracking applied to business studies (Yang and Wang 2015). These authors mapped the intellectual structure of eye tracking research in the business field, using frequency analysis to examine 28 articles from the business discipline that mentioned eye tracking. The articles were sourced from the Social Sciences Citation Index (SSCI) and Science Citation Index (SCI), covering a 14-year period. The second work was by Wang et al. (2016), who conducted a bibliometric study on the role of eye tracking in reading/writing tasks in geo-visualization and cartography, covering the period 1984-2015. Third, Zeng et al. (2018) performed a bibliometric study on scientific trends in VR, which includes eye tracking as one of the most widely-used tools (along with VR) in the last 30 years (1987-2018).

Given this paucity of bibliometric studies in the field of scientific research employing eye tracking, we believe it to be of interest to the scientific community to conduct a specific bibliometric study on this area covering the last three decades, taking into account its obvious usefulness. Specifically, the proposed research questions (RQ) are:

RQ1: Since when has eye tracking been discussed in the marketing literature?

RQ2: Which milestones have marked the most relevant time periods in eye tracking?

RQ3: Which are the most prolific authors and journals with articles published on the application of eye tracking technology in marketing research?

RQ4: What are the themes driving the use of eye tracking in marketing?

RQ5: What are the emerging themes related to eye tracking that will shape future marketing research?

\section{METHODOLOGY}

The following subsections detail the dataset analyzed and its distribution across the different periods under analysis. Subsequently, the co-occurrence of keywords is analyzed, with special emphasis on the generation of science maps that provide an understanding of the results obtained and their interpretation.

\subsection{Data collection}

Conducting bibliometric analyses using secondary information provides a retrospective study. In particular, the WoS database (managed by Clarivate Analysis) is the largest source of international multidisciplinary scientific output (more than 250 disciplines), which offers better retrospective coverage of the subject area (Montero-Díaz et al. 2018) and is geared more toward the English language than other databases. Moreover, WoS includes more than 10,000 journals and comprises three citation databases: Arts \& Humanities Citation, Social Sciences Citation Index, and Science Citation Index Expanded. Scopus, launched by Elsevier Science in 2004, is the major alternative to WoS, with 33 million records (compared to more than 38 million records in WoS). 
Following all these aforementioned authors' recommendations, and having found that the list of records provided by Scopus has an average number of citations per year out of total citations (3.57\% of total) lower than WoS, we opted for WoS to carry out our exhaustive search. ${ }^{1}$ It has previously been used for many other study contexts (e.g., Rodríguez-López et al. 2020 [in the tourism context]; Muñoz-Leiva et al. 2015 [integrated marketing communication]; Del Barrio et al. 2020 [comparative advertising]; and Muñoz-Leiva et al. 2012 [financial marketing]).

A detailed literature review finds a seminal work from the late 1970s in the area of marketing that employs eye tracking tools (Treistman and Gregg 1979), and a further two studies from the 1980s (Young 1984; Bogart and Tolley 1988). In all three cases, the issue of advertising effectiveness is addressed. However, since these early works do not include keywords or abstracts, they are not brought up in the WoS database when the TS field (title, abstract, and keywords) is used as a criterion. Furthermore, the marked growth period for publications on eye tracking related to marketing did not start until 2010. It was for these reasons that we selected 1992 as the starting point of the present bibliometric study, the year of the first article published in marketing research.

In terms of procedure, we downloaded the bibliographic records from the WoS Core Collection from the first indexed manuscript until 2020 for the following queries: TS= (("eye tracking" OR "eye-tracking" OR "eyetracking”) AND (****)) where the field TS refers to a search based on the topic ("title" + "keyword"+ "abstract"), and **** was replaced by these expressions: "marketing", “consumer", “customer", "client", “communication", "advertising”, “advertisement”, "banner", "promotion”, “retail”, "point of sale", "commercial", "web", "product" or "price”. To arrive at a decision regarding the selection of the keywords, a sixstrong panel of experts was formed. This comprised, on the one hand, three experts in eye tracking methodology and research, to determine the different written forms in which the term can be presented, and, on the other, three marketing professors, to determine the generic terms of the four marketing functions to which the main term was to be related.

The rationale for using these partial searches was to obtain an exhaustive set of articles with a view to determining the conceptual structure and evolution of the research across the entire marketing field.

These searches yielded a total of 1,493 articles (without duplications) for the period 1992-2020, which were then read. Those found to have no relation to marketing were discarded. This sift resulted in a final total of 923 marketing-related articles in which the eye tracking methodology was applied, covering the period 1992-2020.

\subsection{Evolution of articles extracted from WoS and the analysis periods selected}

Analysis of the number of publications per year shows that marketing research using eye tracking technology during the

The documents reflected in the WoS database comprise journal articles and book chapters. Our study therefore included both types of documents, but for ease of reference we use the term "article" throughout this paper. 1990s and early 2000s was scant, albeit constant. From 2010, however, it experienced marked growth. Figure 3 shows the number of articles on the topic we identified in WoS for the period 1992-2020.

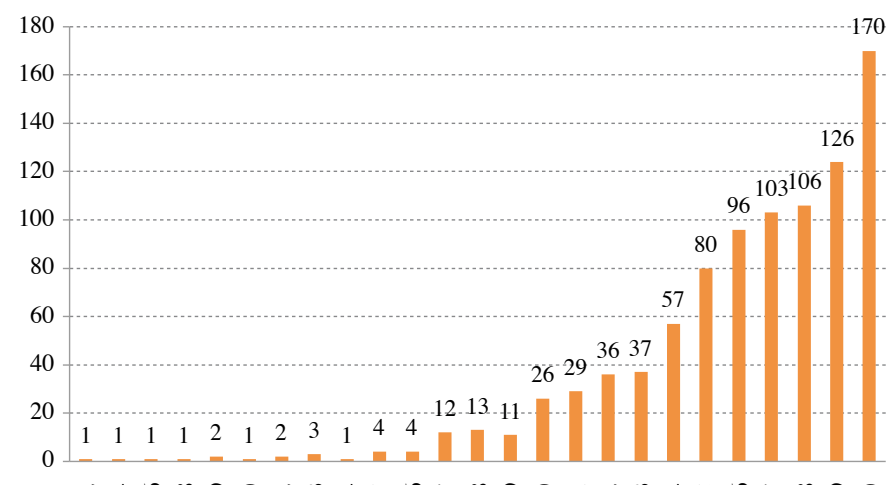

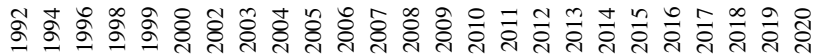

Figure 3

Volume of "marketing" + "eye tracking" articles per year in WoS Source: Own elaboration.

Throughout this period, some important milestones can be identified that have contributed to shaping the evolution of the volume of publications. For example, since 2000, the Swedish high-tech Tobii Technology, which specializes in eye tracking, has been developing new eye trackers that are easier to install and use, featuring intuitive software. But a major turning-point in the evolution of scholarly research on eye tracking came in 2009 when the third international EyeTrackUX conference was held (Comunicae 2009). In this conference, the usability and benefits of eye tracking for different research topics were explained, including those related to e-commerce, market research, and user behavior (ibid.). Although the biennial ETRA (Eye-tracking Research \& Applications) Symposium was created at the beginning of this century, it was not until 2010 that it acquired greater international relevance, bringing together computer scientists, engineers, and behavioral scientists. In addition to these two major events, various computer programs were launched, such as OGAMA. This is open-source software designed to analyze eye and mouse movements for eye tracking studies, which enables the data collected via systems such as Tobii Pro, Smart Eye, EyeTech, Gazepoint, or SMI to be exploited.

Another milestone that marked a point of exponential growth in publications, in 2014, was the launch of Tobii Tech's first eye tracking platform, which was designed to integrate its functionalities into devices such as laptops and monitors, although they were originally focused on the video-game-developer sector. In 2015, some special issues were published in journals such as Journal of Cognitive Psychology ("Developmental eye-tracking research in reading") and, in 2016, in Computer Vision and Image Understanding ("Special issue on visual tracking"). Since then, there have been several calls for papers focused on this research method in various disciplines.

An analysis of specific periods also identified future trends (emerging/declining themes) and relationships that might have seemed insignificant within the context of a broader general 
timeframe as they may be topics that were extensively studied in the past, but less so today-or vice-versa (Echchakoui and Mathieu 2008).

Taking into consideration these technological and academic milestones, we split the entire set of articles into three periods: (1) 1992-2009, (2) 2010-2014, and (3) 2015-2020. Following standard practice in co-word analyses from a longitudinal perspective, we made the first period the longest, to arrive at a sufficient number of published works; we then divided the remaining timeframe into two (approximately) five-year periods to give us a significant volume of articles and capture the major milestones in the development of the discipline. The first period contains 57 articles, the second period 185, and the third period 681 .

\subsection{The co-word analysis procedure}

Co-word analysis was first proposed by Callon et al. (1983). It considers words to be fragments of knowledge (Callon et al. 1991), hence, the frequency with which they appear in a text (or series of texts) points to the relative popularity of topics within a given research field (Ding et al. 2001). This kind of analysis has been successfully applied in different scientific disciplines (Cambrosio et al. 1993; Cobo et al. 2011; Ding et al. 2001; Lee and Jeong 2008; Viedma del Jesús et al. 2011; Yang et al. 2012). Broadly, the methodology we followed involves the following stages:

1. Data recovery: different bibliographic databases can be used at this stage to access all the records, such as the WoS. In our case, the sample of 923 articles we extracted represented 4,673 keywords.

2. Data preprocessing: first of all, incorrect or duplicate records are detected and eliminated. A de-duplicating process (manual, by plural and by Levenshtein distance equal to 1) was applied. Prior to conducting the co-word analysis, we performed a homogenization process to merge plural and singular forms (e.g., "brand"/"brands") and convert acronyms into their full forms or vice-versa. We also undertook a semantic search to group together words with alternative spellings (while keeping the meanings unchanged). Principally, this related to words spelled differently in American vs. British English, such as behavior/behavior, and those that can be written hyphenated or unhyphenated (e.g., eye-tracking/ eye tracking). This stage is particularly complex and requires in-depth knowledge of the phenomenon under analysis because the decisions made at this point will ultimately determine the coherence of the results. Finally, a total of 1,434 keyword groups were subjected to co-occurrence analysis.

3. Data extraction: the researcher focuses on the unit of analysis, which may include the volume of documents and citations, authors, and keywords, for instance.

4. Normalization: Bibliometric indices are calculated, such as the similarity measure (Van Eck and Waltman 2009) and the equivalence index or Jaccard index (Cobo et al. 2012a).

5. Mapping: the objective of science mapping (using strategic maps or thematic networks, for example) is to interpret the scientific quality and productivity of the identified subject areas (Moral-Muñoz et al. 2019). These maps can be cons- tructed through multidimensional scaling (White and McCain 1998), principal component analysis, or cluster analysis (Börner et al. 2003; Kumar et al. 2019 [or even, such as in the latter case, an ANOVA]). The resulting thematic networks are given the name of the most significant keyword.

6. Analysis/visual representation: the thematic network is analyzed and statistical techniques are applied to show the degrees of relationship or overlap between the clusters of keywords. Different techniques and specific software that represent the full science maps and the results of the analyses (such as clustering or partitions) are employed.

7. Longitudinal approach: Comparisons between the different periods can provide insights into how the principal research fields have evolved over the decades.

We performed our co-word analysis (stages 2 to 7) using SciMAT software (Cobo et al. 2012b; Sci2s 2011). SciMAT is an open-source (GPLv3) tool designed by the Sci2s research group at the University of Granada (Cobo et al. 2012b) and is ideal for conducting longitudinal research. It is used for the bibliometric analysis of content based on science mapping, examining the content of publications and identifying the research topics that have attracted the interest of the international academic community.

In the module for carrying out the science mapping analysis, we selected the following options: periods, unit of analysis, data reduction, network type, network reduction, normalization, clustering, among other parameters. Table 1 shows the selected parameters.

Table 1

Selected parameters in SciMAT. Module to manage the knowledge base

\begin{tabular}{|c|c|}
\hline Period selection & $\begin{array}{l}1992-2009 \text { (57 papers), 2010-2014 (185), } \\
\text { and 2015-2020 (681) }\end{array}$ \\
\hline Unit of analysis selection & $\begin{array}{l}\text { Words: Author's words, Source's words, } \\
\text { Added words }\end{array}$ \\
\hline Data reduction & $\begin{array}{l}\text { Minimum frequency for periods: } 2,4 \text {, and } \\
7 \text {, respectively }\end{array}$ \\
\hline Kind of network & Co-occurrence \\
\hline Network reduction & Minimum value: 4 \\
\hline Normalization measure & Equivalence index \\
\hline Clustering algorithm & $\begin{array}{l}\text { Single centers algorithm. Maximum } \\
\text { network size: } 9 \text {. Minimum network size: } 2\end{array}$ \\
\hline Document mapper & Core mapper \\
\hline Quality measures & $\begin{array}{l}\text { Sum citations, average citations, and } \\
h \text {-index }\end{array}$ \\
\hline Longitudinal analysis & $\begin{array}{l}\text { Evolution map: Jaccard's index } \\
\text { Overlapping map: Inclusion index }\end{array}$ \\
\hline
\end{tabular}

\subsection{The science maps extracted}

Co-word analysis enables thematic areas or themes to be traced graphically using strategic diagrams. In the strategic diagram, these thematic areas are represented according to the measures of centrality and density, which position them in a two-dimensional space divided into four quadrants (see Figure 4). 


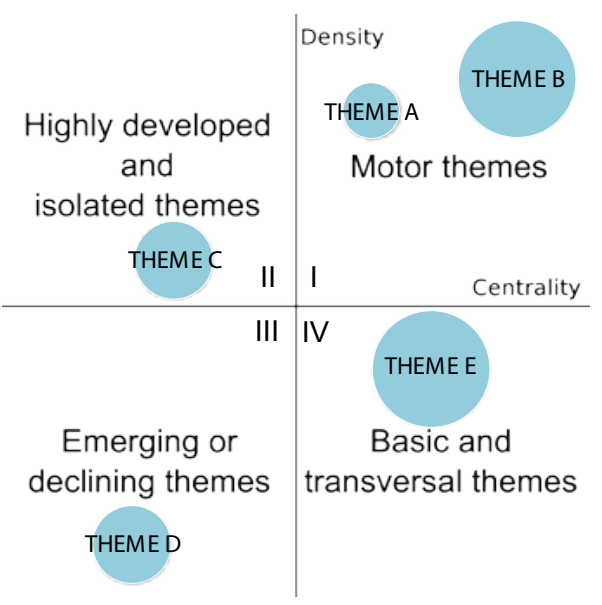

Figure 4

The quadrants of a strategic diagram

Source: Callon et al. (1991) and Cobo et al. (2011).

Centrality is the degree to which the different themes - keyword clusters - are related to each other, while density shows the extent to which the themes are well developed (Montero-Díaz et al. 2018). According to Cobo et al. (2011), the upper-right-hand quadrant (I) contains those themes that are important to the construction of the scientific field, which are known as "motor themes". The themes positioned in the upper-left-hand quadrant (II) are well developed internally, these being specialist - but very peripheral or isolated- subjects. In the lower-left-hand quadrant (III), we find underdeveloped subjects-that is, subjects that are either emerging or declining. Finally, the lower-right-hand quadrant (IV) contains topics that, while significant for the scientific field, are not well developed. They are basic, transversal, and generic subjects. Meanwhile, the thematic network analyzes the interrelationships between the thematic areas reflected in the strategic diagram.

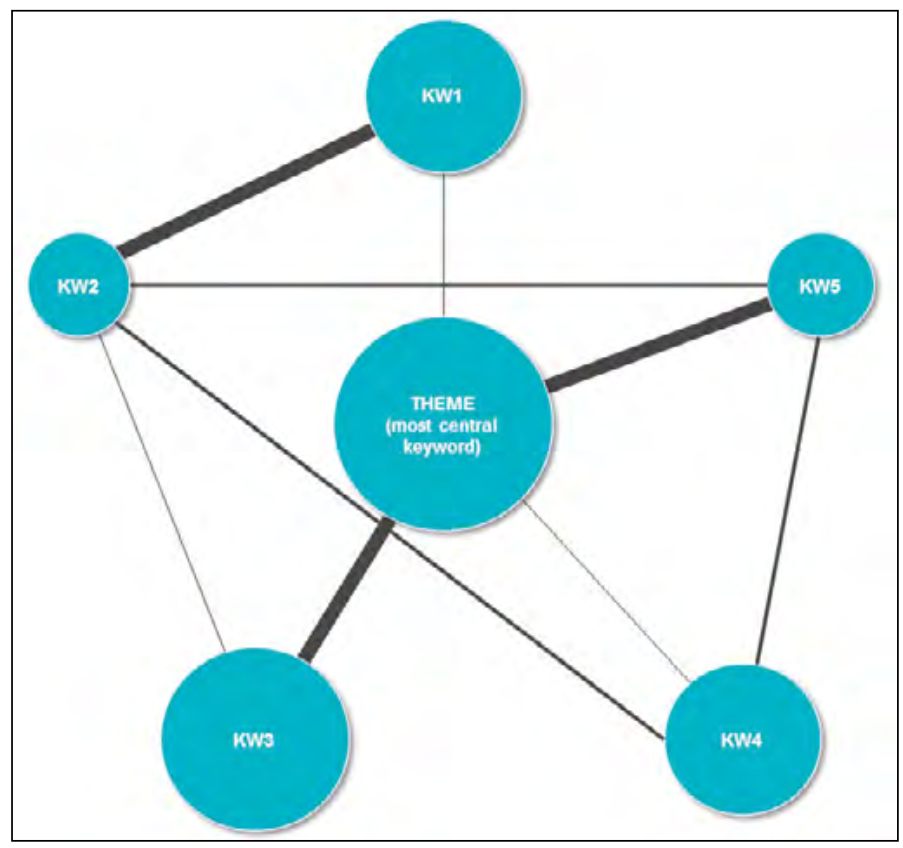

Figure 5

Example of a thematic network, based on keyword (KW) repetition Source: Own elaboration.
These graphs provide the opportunity to track the evolution of a scientific field, classify related topics, and understand how this change or evolve thematically relative to the primary field. Taking this longitudinal approach, we were able to quantify and visually present the thematic evolution of scientific literature that applies eye tracking, to enable other researchers to understand the current state-of-the-art in this area and to predict where future research could lead. Our analysis also reveals the thematic networks, which are labeled according to the most significant keyword (that is, the most central keyword in the cluster).

\section{RESULTS}

\subsection{Analysis of authors and sources}

A performance test identifies the top ten authors (concretely, nine) who have published the greatest number of articles, with Gastón Ares being in first place (see Table 1). This author published 18 articles in the timeframe under analysis, with more than 300 citations in total and almost 18 citations per article (17.67). His most-cited study deals with the influence of gender and age on food purchases (Ares 2007). Given that citation rates are affected by the age of the article in question, to address this effect we calculated the average citation rates per year-that is, the overall number of citations divided by the number of age of the articles, measured as average years since the articles were published (Yan and Ding 2010; Kumar and Polonsky 2017). This approach has been applied in previous marketing-related citation analyses (e.g., Kumar and Polonsky 2017). G. Ares reaches 65.16 citations per year $(\mathrm{C} / \mathrm{Y})$.

Table 2

The top-10 most productive authors with the greatest number of articles and citations

\begin{tabular}{lcccc}
\hline \multicolumn{1}{c}{ Author } & $\begin{array}{c}\text { No. of } \\
\text { articles }\end{array}$ & $\begin{array}{c}\text { No. of } \\
\text { citations }\end{array}$ & $\begin{array}{c}\text { Average no. of } \\
\text { citations per article }\end{array}$ & $\begin{array}{c}\text { Citations } \\
\text { per year }\end{array}$ \\
\hline Ares, Gaston & 18 & 318 & 17.67 & 65.16 \\
Wedel, Michel & 18 & 1388 & 77.11 & 118.63 \\
Pieters, Rik & 16 & 1541 & 96.31 & 116.48 \\
Behe, Bridget K. & 14 & 99 & 7.07 & 21.02 \\
Khachatryan, Hayk & 10 & 50 & 5.00 & 14.29 \\
Antúnez, Lucía & 9 & 208 & 23.11 & 35.31 \\
Giménez, Ana & 9 & 281 & 31.22 & 41.46 \\
Harper, Simon & 8 & 54 & 6.75 & 9.81 \\
Otterbring, Tobias & 8 & 55 & 6.88 & 15.17 \\
Shams, Poja & 7 & 20 & 2.85 & 2.44 \\
\hline
\end{tabular}

The next-most productive authors are Michel Wedel (18; 77.11 average citations; and $118.63 \mathrm{C} / \mathrm{Y}$ ) and Rik Pieters (16; $96.34 ; 116.48)$. These two authors, along with Ralf van der Lans, dealt with the application of eye tracking in psychology in the book chapter entitled "Eye tracking methodology for research in consumer psychology" (Pieters et al. 2019), which reflects the interest in eye movement for analyzing the minds of individuals in their role as consumers. Pieters et al. (1999) modeled the pat- 
tern of visual attention to repeated print advertising, and Pieters and Warlop (1999) focused on attention during brand selection, considering the impact of time pressure and task motivation.

In another study by Wedel, this time as co-author (Wang et al. 2018), it was found that consumers' visual processing of the product brand on a website is significantly determined by their facial expressions and their type of gaze. These authors demonstrated their theory by comparing Chinese and American society, using the eye tracking methodology for their experiment. Yet another study by Wedel, published in 2020 and co-authored with Pieters, examined the distance between the subject's head and the stimulus, combined with eye movements during consumers' exposure to advertising, via two eye tracking studies. The authors found that these subtle backand-forth head movements during ad exposure (nodding in agreement, for instance) were linked to consumers' processing goals and are predictors of subsequent brand memory, independent of eye movements. In lower positions in terms of productivity, we find B. K. Behe (with 14 articles), H. Khachatryan (10), L. Antúnez (9), A. Giménez (9), S. Harper (8), T. Otterbring (8) and P. Shams (7).

The information sources with the largest number of articles published on marketing and eye tracking are presented in Table 2. We can observe that, curiously, the leading source of scientific articles on this topic is the journal Food Quality and Preference (with 26 articles), followed by Journal of Business Research (26), Frontiers in Psychology (23), Computers in Human Behavior (22), Appetite (13), International Journal of Human-Computer Studies (12), Sustainability (12), Behavior \& Information Technology (11), Journal of Eye Movement Research (10), and PLOS ONE (10).

Table 3

The top-10 journals with the greatest number of articles referring to eye tracking (with 10 articles or more)

\begin{tabular}{lccc}
\hline \multicolumn{1}{c}{ Source } & $\begin{array}{c}\text { No. of } \\
\text { articles }\end{array}$ & $\begin{array}{c}\text { \% of articles/ } \\
\text { total table }\end{array}$ & $\begin{array}{c}\text { \% of articles/ } \\
\text { total database }\end{array}$ \\
\hline $\begin{array}{l}\text { Food Quality and Preference } \\
\text { Journal of Business Research }\end{array}$ & 26 & $9.74 \%$ & $2.82 \%$ \\
$\begin{array}{l}\text { Frontiers in Psychology } \\
\text { Computers in Human Behavior }\end{array}$ & 23 & $9.74 \%$ & $2.82 \%$ \\
$\begin{array}{l}\text { Appetite } \\
\text { International Journal of }\end{array}$ & 13 & $8.61 \%$ & $2.49 \%$ \\
$\begin{array}{l}\text { Human-Computer Studies } \\
\text { Sustainability }\end{array}$ & 12 & $4.49 \%$ & $1.30 \%$ \\
$\begin{array}{l}\text { Behaviour \& Information } \\
\text { Technology }\end{array}$ & 12 & $4.49 \%$ & $1.30 \%$ \\
$\begin{array}{l}\text { Journal of Eye Movement } \\
\text { Research }\end{array}$ & 11 & $4.12 \%$ & $1.19 \%$ \\
PLOS ONE & 10 & $3.75 \%$ & $1.08 \%$ \\
\hline Total n. ${ }^{\circ}$ of articles in table & $\mathbf{2 6 7}$ & $\mathbf{1 0 0 . 0 0 \%}$ & $\mathbf{3 0 . 2 6 \%}$ \\
\hline $\begin{array}{l}\text { Total n. }{ }^{\circ} \text { of sources in the } \\
\text { database }\end{array}$ & $\mathbf{4 8 6}$ & - & - \\
\hline
\end{tabular}

Lower down the list of sources, we find journals that are more directly linked to the marketing discipline, such as Journal of Advertising Research (9 articles), Journal of Marketing Research (9), Journal of Retailing and Consumer Services (9), and International Journal of Advertising (8).

\subsection{Co-word analysis}

FIRST PERIOD (1992-2009)

In the first period, there are eight main themes (ordered from highest to lowest centrality): eye movements, brand, eye tracking, attention, persuasion, human-computer interface, web, and thinking (see Figure 6). The motor themes of the upper right-hand quadrant (I) - eye movement, attention, and brand - present a strong degree of interaction with other themes (centrality) and significant internal development (density). The top two themes exceed a thousand citations (1,116 and 1,576, respectively), despite having generated only a modest number of articles (see Table 3 ). This suggests an interest in these topics in the subsequent periods.

Eye movement is the subject with the greatest centrality and density, and the one that is most closely related to other issues such as "information", judging by its corresponding thematic network. The prevalence of interest in eye movement shows it to be a topic of study in its own right, only subsequently becoming a prelude to eye tracking technology (it also indicates a certain relationship with the keyword "tracking technique").

The brand motor theme is ahead of the other themes in this period in terms of the total number of citations (see Table 3 ), and it is studied from the perspective of the visual impact of a brand promotion that appears in different advertisements. The brand and eye-movement research topics both achieve the highest impact index $(h$ index $=13)$.

Attention is also an important theme for the construction of the scientific field, albeit output is still scant in this period (just eight articles). This theme was addressed together with concepts such as "ubiquitous computing", taking a "contextualization" approach to attention, with the intention of improving "perception" using "Bayesian" analysis techniques.

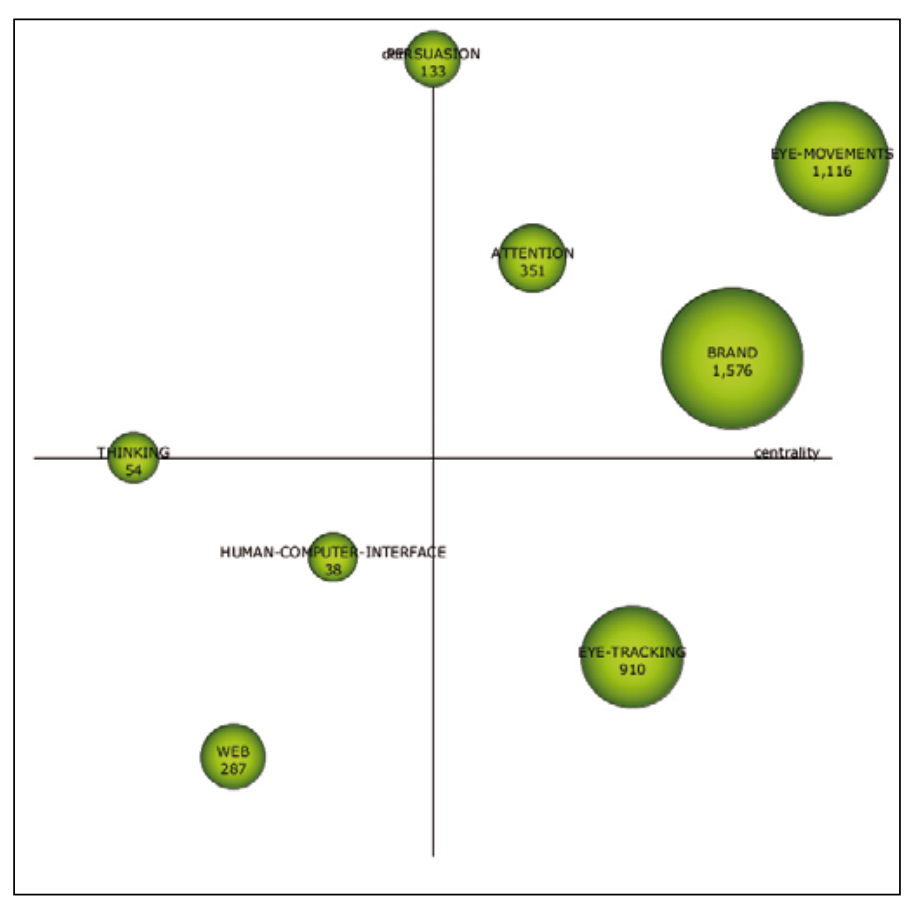

Figure 6

Strategic diagram for the first period (1992-2009): Sum of citations Source: Own elaboration from SciMAT. 
Persuasion is in a relatively undefined position, being located on the "density" axis and therefore not strictly in either of the two adjacent quadrants. The scientific output related to this subject is scant (just two articles) but the density is high, which makes it a theme that appears to have strong and well-established internal links with (and between) its most frequently-mentioned keywords-such as information "processing" or "involvement" with a "moderating effect" (that is, determining factors).

Table 4

Performance of themes in the first period (1992-2009)

\begin{tabular}{lccc}
\hline \multicolumn{1}{c}{ Theme } & No. of articles & $\boldsymbol{h}$ index & $\begin{array}{c}\text { Average no. } \\
\text { of citations }\end{array}$ \\
\hline Eye movements & 15 & 13 & 74.40 \\
Brand & 14 & 13 & 112.57 \\
Eye tracking & 12 & 9 & 75.83 \\
Attention & 8 & 8 & 43.88 \\
Persuasion & 2 & 2 & 66.50 \\
Human-computer interface & 2 & 2 & 190.00 \\
Web & 2 & 2 & 143.50 \\
Thinking & 2 & 2 & 27.00 \\
\hline
\end{tabular}

We find that, in this first period, eye tracking is a basic or generic theme that is underdeveloped internally (that is, with low density), as it is the primary cross-cutting theme in this field of research. Its strongest relationships are with "language", "communication", and "choice" of products (presented in in-store "displays”) (see Figure 7).

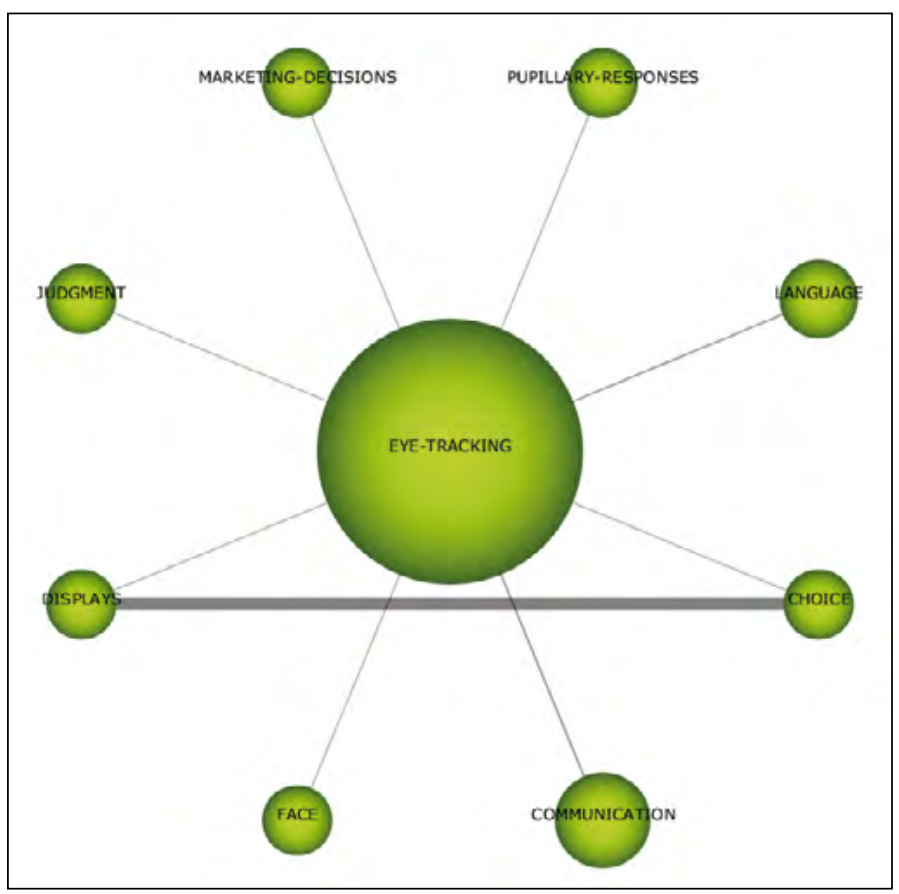

Figure 7

Thematic network for eye tracking (1990-2009). Sphere size is proportional to the sum of citations

Source: Own elaboration from SciMAT.
Finally, human-computer interface, web, and thinking are emerging or declining issues that are underdeveloped and have no strong connection with other themes. Analysis of their evolution in subsequent periods will reveal whether they disappear or indeed prove to be emerging themes. In the case of web, this is clearly an emerging issue, becoming basic or generic in the second period. In the case of thinking, this theme focuses on aspects such as consumer thinking styles or shoplifters' perceptions of anti-shoplifting security measures or their techniques for outmaneuvering them ("thinking thief").

\section{SECOND PERIOD (2010-2014)}

In this period, there are nine primary themes that stand out in particular: attention, choice, web, model, perception, gaze, children, communication, and facial expressions (see Figure 8). Attention is the theme with the highest impact index, followed by visual and gaze (all with a $h$ index over 10; see Table 4).

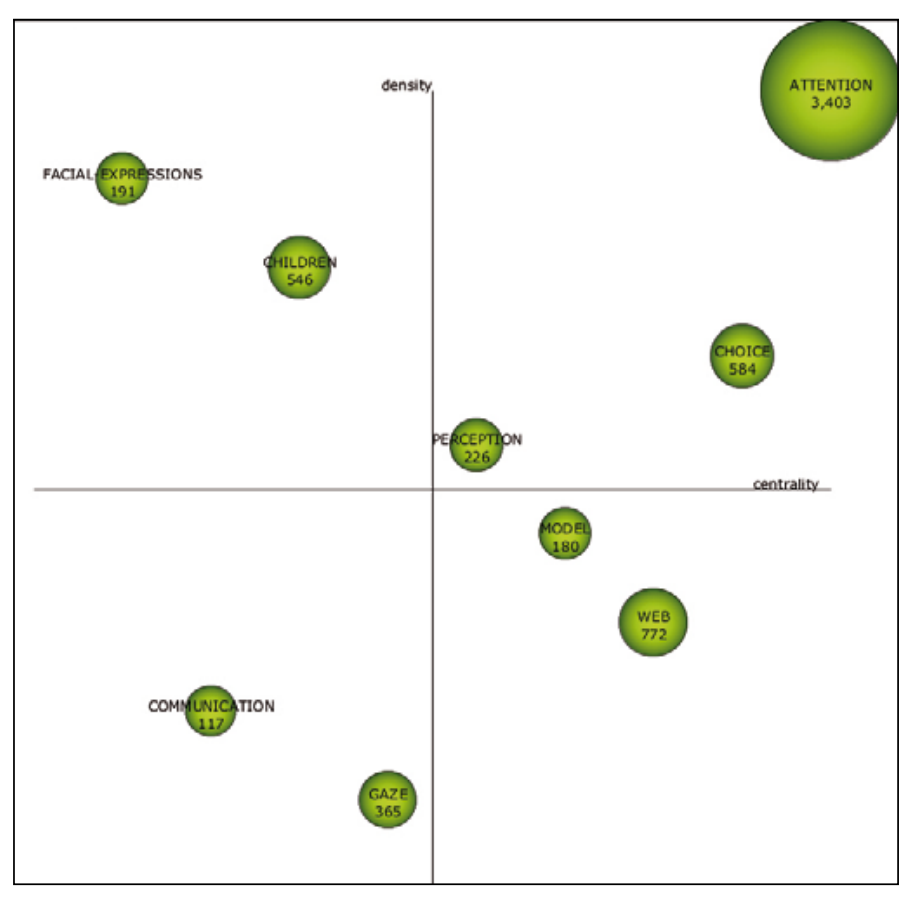

Figure 8

Strategic diagram of second period (2010-2014): Sum of citations Source: Own elaboration from SciMAT.

Compared to the previous period, it can be observed that attention has grown, becoming the main motor theme and the one that has generated the most articles (112), total citations $(3,403)$, and impact $(h$ index $=32$ ). This growing relevance may be due to its strong link with some of the motor themes from the previous period, such as "eye tracking" and "eye movements" (which no longer appear in this period as themes in their own right), as well as with "information" and "brand" (see Figure 9). This close relationship is noticeable, for example - albeit less intensely - in studies on "nutrition", in which eye tracking techniques are used to measure the subjects' attention to "ads" (or advertising messages) (e.g., Ares 2007). 


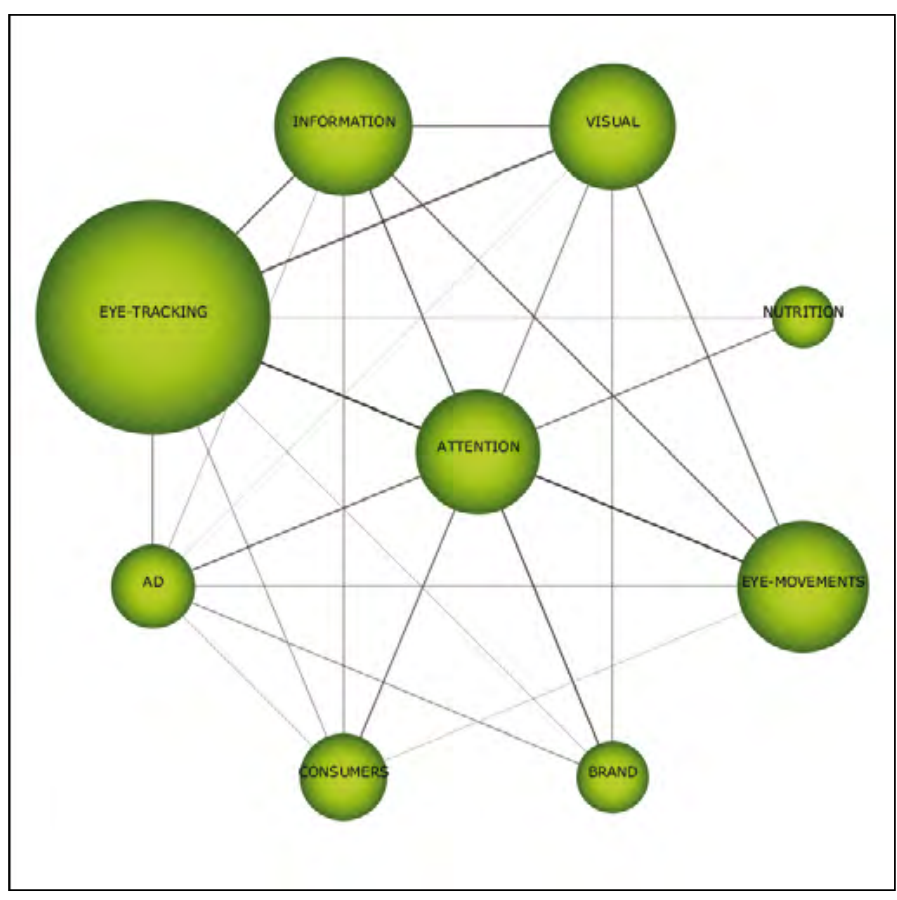

Figure 9

Thematic network for attention (2010-2014). Sphere size is proportional to the sum of citations

Source: Own elaboration from SciMAT.

Choice is another keyword that becomes relevant to the scientific field in this period, having generated a considerable volume of articles, and it is also well developed. It presents links to a large number of topics, primarily "marketing decisions", "preferences", and "time". In the latter case, the time variable is analyzed in studies on consumer attention and choice applied to: risk aversion in gambling; in-store merchandise displays and the effective use of supermarket shelf-space; or VR shopping environments using machine learning.

Perception, while presenting low values of centrality and density, is considered a motor theme studied in the case of the "packaging" and labeling of food and other "products" in marketing, including studies focused on the measurement of aspects such as perceptions of product healthiness (Antúnez et al. 2013).

The World Wide Web and the modeling of consumer perception and attention (model) began to attract the attention of several scholars during this period, becoming basic or generic themes. In the case of the former, the study of the web from an attentional perspective is linked to themes such as "e-commerce", "banner ads", and "usability", from the "user" point of view. The modeling of consumer behavior (model), although with fewer articles, begins to gain more importance among keywords, being linked to issues such as "recall" or memory and applied to different contexts ("contextual").

Children and facial expressions are notable for presenting low centrality yet high density (see Figure 9), occupying the position of specialized or peripheral subjects. This position is also affected by the scant output generated in this period ( 8 and 4 articles, respectively); and these two themes are not related to many other topics. The study of children has mainly arisen as a "target" of different brands or in the study of ASD and how it affects aspects of consumption and product use. Of particular note is the average number of citations that the study of facial expressions has received in relation to the low level of output (4 articles; see Table 4). This is a very specific topic focused on a new technology and methodology, namely facial "recognition" of consumers.

Table 5

Performance of themes in the second period (2010-2014)

\begin{tabular}{lrcc}
\hline \multicolumn{1}{c}{ Themes } & No. of articles & $\boldsymbol{h}$ index & $\begin{array}{c}\text { Average no. } \\
\text { of citations }\end{array}$ \\
\hline Attention & 112 & 32 & 30.38 \\
Choice & 21 & 15 & 27.81 \\
Web & 33 & 15 & 23.39 \\
Model & 7 & 6 & 25.71 \\
Perception & 7 & 5 & 32.29 \\
Gaze & 9 & 8 & 40.56 \\
Children & 8 & 8 & 68.25 \\
Communication & 4 & 4 & 29.25 \\
Facial expressions & 4 & 4 & 47.75 \\
\hline
\end{tabular}

Communication and gaze are themes that, being found in the lower left-hand quadrant, can be said to be emerging or declining. In this period, human emotions begin to be studied from the gaze, this clearly being an emerging topic for future research. In this period, we can observe that gaze has developed significantly and is beginning to generate interest and build a certain profile, judging by its impact index, which is higher than that of other motor themes (see Table 4), based on a significant number of articles (9). We can also see the beginnings of links to other topics such as "social". Communication is fundamentally linked to the term comprehension. However, it is necessary to continue observing the evolution of this theme in the following period to determine its nature or current position.

\section{THIRD PERIOD (2015-2020)}

In general, eight main research themes can be observed in this period: the eye tracking tool itself, perception, labeling, ad, communication, online, model, and smokers (see Figure 10 and Table 5). The appearance of eye tracking as a motor theme is highlighted as, in the first period, this was a basic theme that was underdeveloped internally (albeit with several external links), and, in the second period, it grew, becoming linked to attention. Now, it appears to be more internally and externally developed than attention, while maintaining a close relationship to it (see Figure 11).

In terms of performance, eye tracking presents the highest indicators for quantity and quality (393 articles; 2,318 citations; $h$ index $=21$; see Table 5). This theme is very well developed and highly connected to other themes such as "consumers", "visual" matters, "information" "web", "choice", and "brand", as well as, of course, "attention", "visual", and "eye-movements". Another theme with high centrality and density (quadrant I) is $a d$, which 
is currently strongly related to "banner ad", "recall", "attitudes" and "persuasion", from a "neuromarketing" approach. It appears in a large number of articles (65) and has received a relatively high number of citations (364).

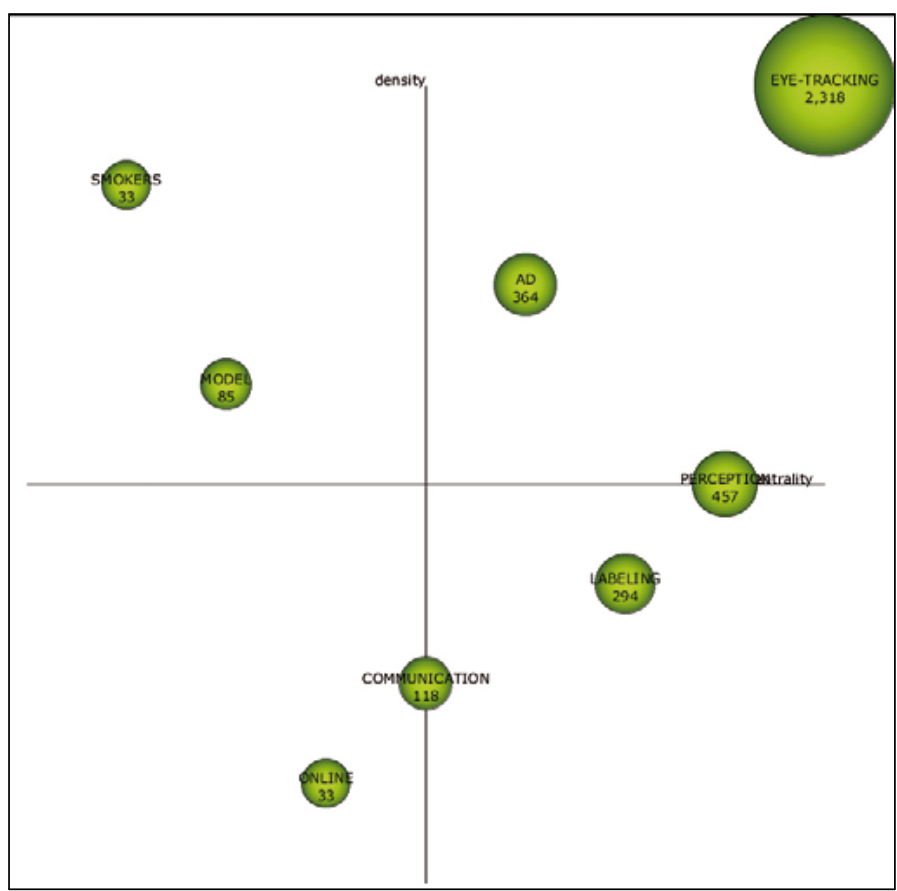

Figure 10

Strategic diagram of the third period (2015-2020). Sum of citations (sphere size is proportional to the sum of citations)

Source: Own elaboration from SciMAT.

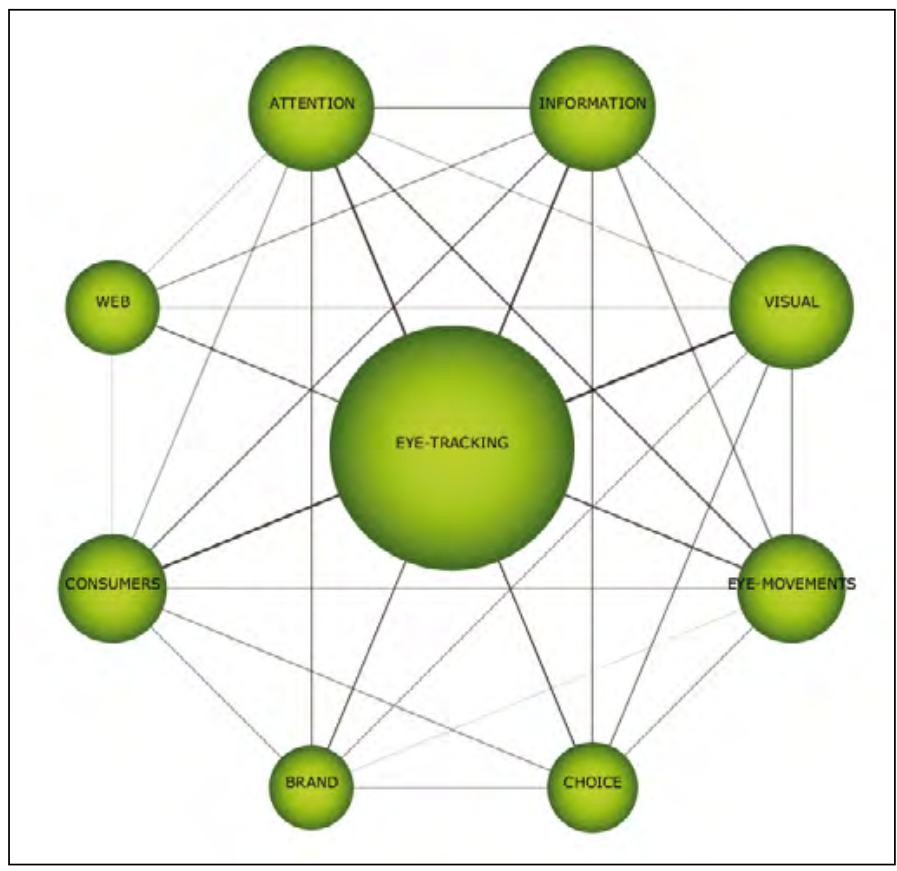

Figure 11

Thematic network for eye tracking (2015-2020). Sphere size is proportional to the sum of citations

Source: Own elaboration from SciMAT.
Among the most important and well-developed themes is perception. This theme is related to other topics including "food', "nutrition, "products", and "image", and presents a relatively high value in terms of output (58 articles) and impact (2,318 total citations; 7.88, on average; $h$ index: 13 ).

Labeling is another generic topic (quadrant IV), studied from the point of view of the consumer's "willingness" or "preferences". Communication presents no major changes in its evolution, maintaining the same position as in the previous period. Due to the greater number of publications and citations (during the most recent period), we believe communication to be one element of the marketing mix for which eye tracking will continue to be an in-demand topic and, therefore, an emerging theme, although we expected it to branch off into even more specific topics (such as banner ad, promotions, e-merchandising, ads in VR, and so on).

Turning to the online context itself, as this has no link to previous periods, it presents something of a dilemma: is this an emerging or a declining issue? In either case, this field of study will continue to exist in the future to a greater or lesser degree. The primary link of this theme is with the "user" approach.

As a specialized and peripheral topic (quadrant II), we find model, which is an emerging theme that presents connections with the topics "valuation" and "search". Finally, smokers and, more specifically, the smoking habit, has been a recurring theme in this period that, unsurprisingly, appears closely linked to "cigarette" and "tobacco".

Table 6

Performance of themes in the third period (2015-2020)

\begin{tabular}{lccc}
\hline \multicolumn{1}{c}{ Themes } & No. of articles & $\boldsymbol{h}$ index & Average no. of citations \\
\hline Eye tracking & 393 & 21 & 5.90 \\
Perception & 58 & 13 & 7.88 \\
Labeling & 42 & 8 & 7.00 \\
Ad & 65 & 9 & 5.60 \\
Communication & 25 & 6 & 4.72 \\
Online & 9 & 4 & 3.67 \\
Model & 16 & 6 & 5.31 \\
Smokers & 12 & 3 & 2.75
\end{tabular}

\subsection{Analysis of the evolution of marketing research involving eye tracking}

Using SciMAT, as well as detecting topics and analyzing them by periods, it is possible to trace their evolution over time (see Figure 12). We can observe, for instance, that the marketing research involving eye tracking presents a certain degree of cohesion between one period and another, as several of the themes identified are grouped under thematic areas that appear in the previous and/or subsequent period. These are central elements around which the rest of the topics discussed above are articulated.

Solid lines indicate a thematic nexus based on the fact that both themes (or clusters) share the same name, or the name of one theme is part of the other. The dotted lines indicate that the 
themes are related because they share keywords. The thickness of the lines is proportional to the Inclusion Index, and the volume of the spheres is proportional to the number of articles on each topic (Murgado-Armenteros et al. 2015).

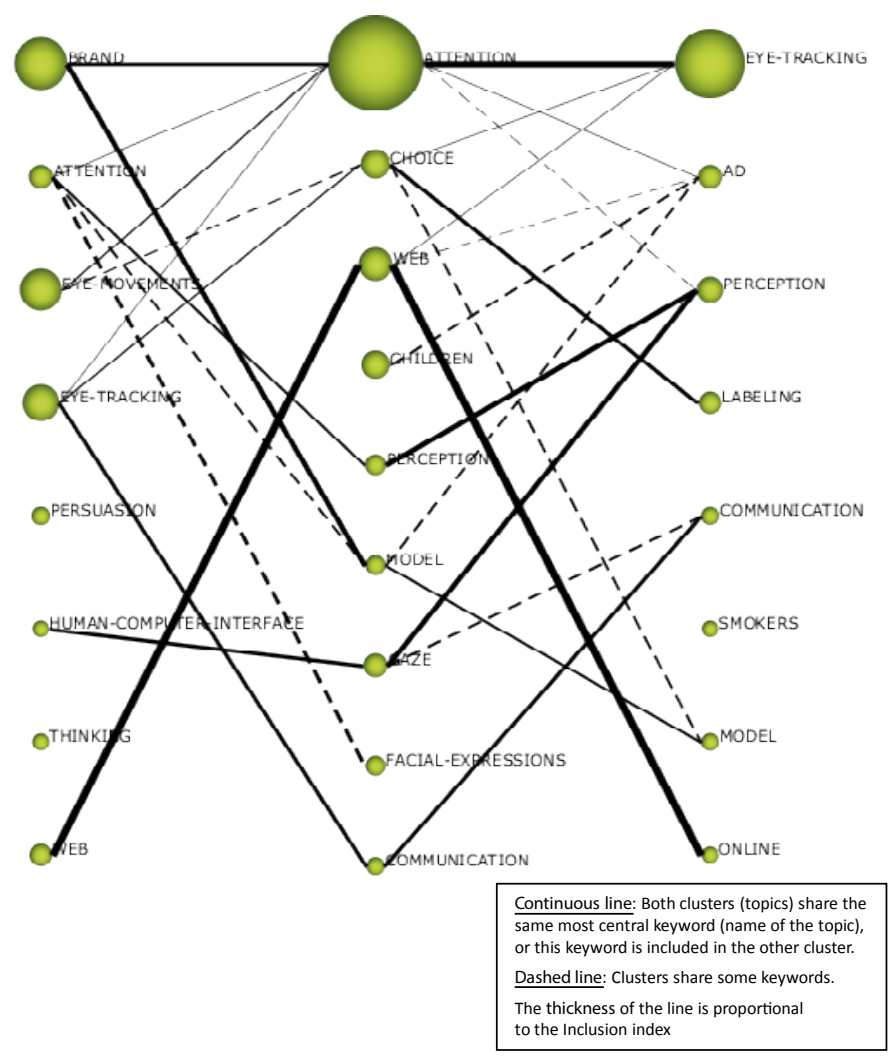

Figure 12

Longitudinal evolution map for research involving eye tracking (sphere size is proportional to the sum of citations)

Source: Own elaboration from SciMAT.

The thematic areas we identified are as follows:

-Brand-attention-modeling. To analyze the evolution of attention, it is first necessary to identify a brand. Brand began as an important motor theme in marketing-related research using an eye tracking methodology, and also in research addressing different effects of pictorial shape and font size (e.g., Pieters and Wedel 2004). Hence, its relevance lies in the attention consumers pay to brand information or advertising (Teixera et al. 2010). In recent years, brand has also been a fundamental pillar in studies that employ eye tracking in the field of marketing thanks to technological advances, seeking to model consumer behavior in relation to the brands in question. Some studies have developed simulation models (artificial neural network models) to predict the impact of gaze in the case of dynamic marketing (Brousseau et al. 2020; Rumpf et al. 2020). Derived from this, consumer neuroscience or neuromarketing comes into play, where the motor theme eye tracking enjoys a prominent role in recording the activations that are triggered in the brain during the construction of the brand (Hafez 2019). Attention began as an underdeveloped motor theme; subsequently, the research focused on aspects of consumer attention; and, ultimately, it became a well-developed motor theme that continues to be linked to various aspects such as consumer decision-making, visual aspects of online behavior, and attention to advertisements.

-Eye tracking-movements-communication. The evolution of eye tracking cannot be analyzed divorced from the concept of eye movement as the origin and object of study. These are two concepts that are inexorably bound together. Eye movement is the source of interest in the use of this technology, which is why it was the main motor theme of the first period, with subsequent application in studies on consumer attention to information, brands, and advertisements, as noted earlier. In the most recent period, it became almost synonymous with eye tracking, this latter term being used to a greater extent. Eye tracking as a topic was born out of strong and highly-diverse research interests such as the search for the influence of eye-fixation on language development (Stagg et al. 2014) or the influence of various information-search techniques in the process of product selection and purchase (Reisen et al. 2008). Over time, studies that employ eye tracking in the marketing field have formed a direct relationship with attention to brand or product communications stimuli, which explains the cohesion of the eye tracking topic with communication, and how the latter affects the consumer decision-making process (Siegrist et al. 2015).

- Web-online first appears as emerging themes in the first period, coinciding with the arrival of Web 2.0 in 2004. They have remained present throughout all three periods, focused on monitoring users' viewing of web pages during browsing and making recommendations relating to website design (Tazanidou et al. 2005).

- HCI-gaze-perception. Perception is a cohesive but underdeveloped theme that began to build interest from the earliest studies on attention, in the quest to address the possible differences in the processing of different stimuli between-subjects. This question generated a noticeably higher level of interest in the last period, although it is still not well developed. Its evolution shows a certain relationship with gaze in the second period and with human-computer interface in the first.

- Choice-labeling. Choice is another keyword that became a relevant topic for the scientific field and was also well developed in the second period. It maintains connections with a large number of topics, mainly with "marketing decisions", "preferences", and "time". In the last period, it presents a certain association with labeling-another generic topic studied from the point of view of consumer preferences.

\section{MAIN CONCLUSIONS}

The purpose of this research was to offer a synthesis of the evolution of eye tracking as a methodology and research topic in marketing, taking a bibliometric approach-specifically, using the co-word analysis technique. The study addresses the research gap in this field of knowledge, thereby fulfilling the proposed objective. The main conclusions derived from the review of the published academic literature and the co-word analysis are detailed next. 


\subsection{Principal findings from the literature related to eye tracking}

The fact that the sophistication of the eye tracking device itself has evolved in parallel with broader technological developments - giving rise to more than half a dozen types of devices in just over two decades - suggests that the perceived utility of this tool has called for ever-improving precision. This is also evident in the sheer volume of studies that use this method of analysis and in the multidisciplinary nature of its use, which further enhances its benefits. The need to better understand human beings' decision-making processes, behaviors, and skills has been the primary driver for many academics and researchers.

Hence, more than 15,000 scientific articles from more than 100 scientific areas, published from the 1960s to the present day, have involved eye tracking. Out of the total output, which has witnessed continued growth, it is the marketing-related studies that carry particular weight, given the highly transversal nature of this discipline.

One example of this phenomenon is that the most prolific author in research using eye tracking in marketing, G. Ares, has generated almost half the number of articles published by the author with the most publications on eye tracking out of all areas in general (K. Holmqvist). Also noteworthy is the work of R. Pieter and M. Wedel, both singly and in joint authorship (e.g., Peter \& Wedel 2004; 2008). Another marker of the importance of research using eye tracking in marketing is that, in general, scientific centers and universities in the United States constitute the primary source of research using this methodology. The University of Maryland occupies fourth place worldwide in terms of conducting the most eye tracking studies in the marketing discipline (Galesic et al. 2008; Bergstrom and Schall 2014). It should be noted that eye tracking technology has not been available to all research centers; however, over time, its accessibility (along with its capabilities and ease of use) has improved.

The focus of this study and future research can be contextualized in neuromarketing, which is an area of science that investigates the brain and neural responses to stimuli related to aspects of the market (Zurawicki 2010), such as advertising impact or consumer segmentation. The term was coined by scholars in the 2000s (see Phan et al. 2002), hence this scientific discipline is said to have been born in that period. However, the possibilities of applying neuroscience for commercial marketing purposes were already being exploited in the late 1990s. Magnetic resonance imaging, for example, was used for marketing applications, forming part of the toolkit —among which was eye tracking technology - used to measure neurological reactions to controlled stimuli.

Since its very origins, the application of eye tracking has focused mainly on the field of health and psychology. The effects of the use and consumption of health products, the direction of the eyes when reading texts (Copeland and Gedeon 2014), and the analysis of certain disorders (for example, ASD or fragile X syndrome; Farzin et al. 2009) have all been the subject of research that was conducted with the early eye tracking technologies. However, these works are beyond the scope of the marketing discipline and its sectoral policies or extensions.

From the marketing point of view, this tool was initially used for brand analysis, to determine the factors that shape brand per- ception (such as texts and images) and thus influence consumers (Pieters and Wedel 2004). Subsequently, while this approach did not change per se, its field of application broadened out, being used in specific subject areas such as tourism marketing, in general, "e-tourism” websites (e.g., Muñoz-Leiva et al. 2018; 2019), or online search behavior with search engines (e.g., Flavián et al. 2011).

Focusing our attention on this discipline, we can observe that the advertising of the 1990s evolved in line with the changes occurring in society. For example, brands sought to broaden their horizons and reach a wider audience, and to achieve this they introduced elements such as music and striking colors in their external communications in a bid to awaken emotions among consumers. As a consequence, the interest of researchers was focused on identifying the factors that aroused the feelings of customers, by using screen-mounted cameras and other tools from neuroscience.

\subsection{Discussion of co-word analysis results}

Scholarly interest in eye tracking as a research tool continued to grow during the first period (1992-2009). The main interest in the use of eye tracking in marketing revolved around the analysis of attention, in relation to texts or information, for example from product labels; the visual dimension of the commercial distribution realm within establishments (posters and displays) and also on websites; and in advertising. In particular, advertising evolved hand-in-hand with communication media themselves, from cinema, television, and print, to the online and digital environment including social networks. The change in advertising media caused a shift in interest, toward a more creative audiovisual perspective where eye tracking was used to analyze the visual impact of brands in advertisements (Hafez 2019). Therefore, the interest in attention was also increasingly directed toward the digital context.

In the second period (2010-2014), the interest in eye tracking was sustained but, this time, as a tool necessary for other areas of study. Here, "(visual) attention" was the expression with the greatest centrality (motor theme), establishing strong links with other issues related to marketing. In this period, eight other principal themes stand out: choice, web, model, perception, gaze, children, communication, and facial expressions. Eye tracking techniques were widely used to measure subjects' attention to advertising messages (Ares 2007). The study of consumer choice, consumer decision-making in terms of preferences, and the impact of time on attention all attracted significant interest among the scientific community. Perception was another motor theme whose study was applied to the case of food packaging and labeling and other products in marketing, including some studies measuring aspects such as consumer perceptions of product healthiness (Antúnez et al. 2013).

The web also began to attract the attention of several researchers during this period, becoming a basic or generic theme. Other specific topics, such as children, were studied in their capacity as a target for different brands. Facial expressions, meanwhile, was another very specific topic during this period that was concerned with a new methodology or technology based on consumer facial recognition. Also in this period, human emotions 
began to be studied from the perspective of the gaze, this clearly being an emerging topic for future research.

In the third period (2015-2020), eight main themes are observed: eye tracking, perception, labeling, ad, communication, online, model, and smokers. The reappearance of eye tracking itself as a motor theme is of particular note, this having been a basic and internally-underdeveloped theme in the first period. Another theme of great centrality and density is $a d$, which is currently strongly related to banner, recall, attitudes, and persuasion, in some instances examined from a neuromarketing perspective.

The perception theme is related to other topics such as food, nutrition, products, and image, with a relatively high level of output. $L a-$ beling is another generic topic, studied from a consumer preference point of view. Communication evolves stably, maintaining the same position as in the previous period, being a fundamental element of all marketing activities for which eye tracking will continue to generate interest, rendering it an emerging issue. In the future, however, it is expected to fragment into more specific topics such as banner ad, promotions, e-merchandising, ads in $V R$, and so on.

\subsection{Future research}

The online context will continue to exist as a field of study in the future to a greater or lesser extent, accentuated by the current health crisis caused by the COVID-19 pandemic. The strongest link of this theme is with the "user" approach. The smoking habit (smokers) has been a highly recurring specific theme in this period. Lastly, modeling as a tool is an emerging theme with strong connections to the "valuation" and "search" themes.

The present longitudinal analysis showed that there are five thematic areas that appear in at least two of the periods analyzed: (a) brand-attention-modeling, (b) eye tracking-movements-communication, (c) web-online, (d) HCI-gaze-perception, and (e) choice-labeling.

The future of research on marketing research using eye tracking needs to attain deeper levels of understanding of human behavior, and, in this regard, we predict that it will turn to the study of consumer emotions. We recommend that work continues to explore the perceptions of subjects, using ocular metrics, as this topic has been well received as a line of research in recent years. We can observe that it is an internally-underdeveloped subject about which many questions still remain, for example concerning the relationships between beliefs $\rightarrow$ attention $\rightarrow$ recall $\rightarrow$ beliefs.

We also note that, in the most recent research, the use of eye tracking in marketing cannot be separated from neuromarketing. The current trend is to simultaneously apply different reaction-measurement methodologies (Izaguirre-Torres et al. 2020), hence the interest in studying attention to advertisements - to determine the brain activity generated by advertising impact - has, in turn, fostered interest in eye tracking. Thanks to this trend, not only can human behavior be identified but also predicted. From a more market-oriented perspective, future research should focus on providing better value-propositions that increase consumer satisfaction and general well-being in society. One such potential research topic is "neuroethics", which, although widely studied since the 1990s, is only referenced in one or two eye tracking studies, which makes it a topic with great potential for future research.

\section{ACKNOWLEDGEMENTS}

This work was partly supported by the Spanish National Research Programme $(\mathrm{R}+\mathrm{D}+\mathrm{i}$ Research Project ECO201788458-R, "NeuroTourism project") and the Andalusian $\mathrm{R}+\mathrm{D}+\mathrm{I}$ Research Programme (Grant No: B-SEJ-209-UGR18, "Research in NeuroSOCOM" project).

\section{REFERENCES}

Antúnez L., Vidal, L., Sapolinski, A., Giménez, A., Maiche, A., and Ares, G., 2013. How do design features influence consumer attention when looking for nutritional information on food labels? Results from an eye-tracking study on pan bread labels. International Journal of Food Sciences and Nutrition, 64(5), 515-527.

Ares, G., 2007. Influence of gender, age and motives underlying food choice on perceived healthiness and willingness to try functional foods. Appetite, 49(1), 148-158.

Bogart, L., and Tolley, B.S., 1988. The search for information in newspaper advertising. Journal of Advertising Research, 28(2), 9-19.

Bolz, M., Kriechbaum, K., Simader, C., Deak, G., and Lammer, J., 2010. In vivo retinal morphology after grid laser treatment in diabetic macular edema. Ophthalmology, 117(3), 538-544.

Börner, K., Chen, C., and Boyack, K. W., 2003. Visualizing knowledge domains. Annual Review of Information Science and Technology, 37(1), 179-255.

Brousseau, B., Rose, J., and Eizenman, M., 2020. Hybrid Eye-Tracking on a Smartphone with CNN Feature Extraction and an Infrared 3D Model. Sensors, 20(2), 543. https://doi.org/10.3390/s20020543.

Callon, M., Courtial, J., and Penan, H., 1995. Cienciometría, Trea, Gijón.

Callon, M., Courtial, J. P., and Laville, F., 1991. Co-word analysis as a tool for describing the network of interactions between basic and technological research - the case of polymer chemistry. Scientometrics, 22(1), 155-205.

Callon, M., Courtial, J.P., Turner, W.A., and Bauin, S., 1983. From Translations to Problematic Networks: An Introduction to Co-word Analysis. Social Science Information, 22(2), 191-235.

Cambrosio, A., Limoges, C., Courtial, J.P., and Laville, F., 1993. Historical scientometrics? Mapping over 70 years of biological safety research with co-word analysis. Scientometrics, 27(2), 119-143.

Chandon, P., Hutchinson, J. W., Bradlow, E. T., and Young, S. H., 2009. Does in-store marketing work? Effects of the number and position of shelf facings on brand attention and evaluation at the point of purchase. Journal of marketing, 73(6), 1-17.

Clay, V., Kömig, P., and Koeming, S., 2019. Eye Tracking in Virtual Reality. Journal of Eye Movement Reaseach, 12(1), p. 3.

Cobo, M.J., López-Herrera, A.G., Herrera, F., and Herrera-Viedma, E., 2012a. A note on the its topic evolution in the period 2000-2009 at T-ITS. IEEE Transactions on Intelligent Transportation Systems, 13(1), 413-420.

Cobo, M.J., López-Herrera, A.G., Herrera, F., and Herrera-Viedma, E., 2012b. SciMAT: A new Science Mapping Analysis Software Tool. Journal of the American Society for Information Science and Techno$\log$, 63(8), 1609-1630.

Cobo, M. J., López-Herrera, A. G., Herrera-Viedma, E., and Herrera, F., 2011. An approach for detecting, quantifying, and visualizing the evolution of a research field: A practical application to the fuzzy sets theory field. Journal of Informetrics, 5(1), 146-166.

Comunicae, 2009. EyeTrackUX2009, Conferencia internacional sobre eye tracking. Barcelona. https://www.comunicae.es/nota/eyetrackux-2009-la-conferencia-internacional-sobre-eye-tracking-1004395/ 
Copeland, L., and Gedeon, T., 2014. What are you reading most: attention in eLearning. Procedia Computer Science, 39, 67-74 (2014).

Cyr, D., Head, M., and Larios, H., 2010. Colour appeal in website design within and across cultures: A multi-method evaluation. International journal of human-computer studies, 68(1-2), 1-21.

Cyr, D., Head, M., Larios, H., \& Pan, B. (2009). Exploring human images in website design: a multi-method approach. MIS quarterly, 539-566.

Dalton, K.M., Nacewicz, B.M., Alexander, A.L., and Davidson, R.J., 2007. Gaze-Fixation, Brain Activation, and Amygdala Volume in Unaffected Siblings of Individuals with Autism. Biological Psychiatry, 61(4), 512-520. https://doi.org/10.1016/j.biopsych.2006.05.019.

Del Barrio-García, S., Muñoz-Leiva, F., and Golden, L., 2020. A review of comparative advertising research 1975-2018: Thematic and citation analyses. Journal of Business Research, 121(12), 73-84.

Ding, Y., Chowdhury, G. G., and Foo, S., 2001. Bibliometric cartography of information retrieval research by using co-word analysis. Information processing \& management, 37(6), 817-842.

Drusch, G., Bastien, J. C., and Paris, S., 2014. Analysing eye-tracking data: From scanpaths and heatmaps to the dynamic visualisation of areas of interest. Advances in science, technology, higher education and society in the conceptual age: STHESCA, 20(205), 25.

Echchakoui, S., and Mathieu, A., 2008. Marketing trends: Content analysis of the major journals (2001-2006). Proceedings of Administrative Sciences Association of Canada, Nova Scotia, May 27-28, 114-126.

Espigares-Jurado, F., Muñoz-Leiva, F., Correia, M., Sousa, C., Ramos, C., and Faísca, L., 2020. Visual attention to the main image of a hotel website based on its position type of navigation and belonging to Millennial generation: An eye tracking study. Journal of Retailing and Consumer Services, 52, 101-906.

Farzin, F., Rivera, S.M., and Hessl, D., 2009. Brief Report: Visual Processing of Faces in Individuals with Fragile X Syndrome: An Eye Tracking Study. Journal of Autism and Developmental Disorders, 39(6), 946-952.

Flavián, C., Gurrea, R., and Orús, C., 2011. Analyzing the emotional outcomes of the online search behaviour with search engines. Computers in Human Behavior, 27(1), 540-551. https://doi.org/10.1016/j. chb.2010.10.002

Flir, 2016. Refinación del rendimiento del rastro ocular con Chameleon3 USB 3.1. Retrieved from: https://www.flir.es/discover/iis/machine-vision/ refining-eye-tracking-performance-with-the-chameleon3-usb-3.1/

Galesic, M., Tourangeau, R., Couper, M. P., and Conrad, F. G., 2008. Eye-tracking data: New insights on response order effects and other cognitive shortcuts in survey responding. Public opinion quarterly, 72(5), 892-913.

Garfield, E., 1990. Current comments. Keywords plus-ISIS breakthrough retrieval method. 1. Expanding your searching power on current-contents on diskette. Current Contents, 32, 295-299.

Gascó, V., 2020. Herramientas de mapas de calor y eye tracking para optimizar ventas. Saleslayer. Retrieved from: https://blog.saleslayer. com/es/herramientas-mapas-de-calor-eye-tracking

Glanzel, W., 2015. Bibliometrics-aided retrieval: Where information retrieval meets scientometrics. Scientometrics, 102, 2215-2222.

Hafez, M., 2019. Neuromaketing: A new avatar in branding and advertisement. Pacific Business Review International, 12, 58-64.

Hassan, Y., and Herrero, V., 2007. Eye-tracking en Interacción Persona-Ordenador. Máster Universitario Online en Diseño de Experiencia de Usuario. Universidad Internacional de la Rioja.

Hernández-Méndez, J., and Muñoz-Leiva, F., 2015. What type of online advertising is most effective for eTourism 2.0? An eye tracking study based on the characteristics of tourists. Computers in human Behavior, 50, 618-625.
Holmqvist, K., Nyström, M., Andersson, R., Dewhurst, R., Jarodzka, H., and Van de Weijer, J., 2011. Eye tracking: A comprehensive guide to methods and measures. Oxford University Press, Oxford.

Izaguirre-Torres, D., Málaga-Juárez, J., Ricardo Chuqui-Diestra, S., Velasquez-Ccosi, P.F., and Siche, R., 2020. Neuroscience in the advertising of agri-food products: A beneficial tool or a public health hazard?. Scientia Agropecuaria, 11(4), 629-639.

Joseph, A. W., and Murugesh, R., 2020. Potential Eye Tracking Metrics and Indicators to Measure Cognitive Load in Human Computer Interaction Research. Journal of Scientific Research, 64(1), 168-175.

Juárez Varón, D., Tur-Viñes, V., and Mengual, A., 2019. Análisis del diseño de packaging de juguete educativo, mediante neuromarketing. Cuadernos Latinoamericanos de Administración, 15(28).

Just, M.A., and Carpenter, P.A., 1992. Una teoría de la capacidad de comprensión: diferencias individuales en la memoria de trabajo. Psychological Review, 99(1), 122-149.

Kumar, P., and Polonsky, M. J. 2017. An analysis of the green consumer domain within sustainability research: 1975 to 2014. Australasian Marketing Journal, 25(2), 85-96.

Kumar, P., Sharma, A., and Salo, J., 2019. A bibliometric analysis of extended key account management list. Industrial Marketing Management, 82, 276-292.

Lai, M.L., Tsai, M.J., Yang, F.Y., Hsu, C.Y., Liu, T.H., Lee, S.W.Y, Lee, M.H., Chiou, G.L., Liang, J.C., and Tsai, C.C., 2013. A review of using eye-tracking technology in exploring learning from 2000 to 2012. Educational Research Review, 10, 90-115. https://doi.org/10.1016/j.edurev.2013.10.001.

Lee, B., and Jeong, Y. I., 2008. Mapping Korea's national R\&D domain of robot technology by using the co-word analysis. Scientometrics, 77(1), 3-19.

Leone, R.P., Robinson, L.M., Bragge, J., and Somervuori, O., 2012. A citation and profiling analysis of pricing research from 1980 to 2010. Journal of Business Research, 65, 1010-1024.

Matthews, O., Dovies, A., Vigo, M., and Harper, S., 2020. Unabtrusive arousal detection on the web using pupillary response. International Journal of Human-Computer Structure, 136, 102361.

Montero-Díaz J., Cobo M., Gutiérrez-Salcedo M., Segado-Boj F., Herrera-Viedma E., 2018. A science mapping analysis of 'Communication' WoS subject category (1980-2013). Comunicar, 26(55), 81-91.

Moral-Muñoz, J.A., Herrera-Viedma, E., Santisteban, A., and Cobo, M.J., 2020. Software tools for conducting bibliometric analysis in science: an up-to-date- review. El Profesional de la Información. 29(1) e290103. https://doi.org/10.3145/epi.2020.ene.03

Moral-Muñoz, J.A., López-Herrera, A.G., Herrera-Viedma, E., and Cobo, M.J., 2019. Science mapping analysis software tools: A review, in Springer handbook of science and technology indicators, 159-185. Retrieved from: https://doi.org/10.1007/978-3-030-02511-3.

Muñoz-Leiva, F., Hernández-Méndez, J., and Gómez-Carmona, D., 2019. Measuring advertising effectiveness in Travel 2.0 websites through eye-tracking technology. Physiology and Behavior, 200(1), 83-95. https://doi.org/10.1016/j.physbeh.2018.03.002

Muñoz-Leiva, F., Liébana-Cabanillas, F., and Hernández-Méndez, J., 2018. Etourism advertising effectiveness: Banner type and engagement as moderators. Journal of Services Marketing, 32(4), 462-475. https://doi.org/10.1108/JSM-01-2017-0039

Muñoz-Leiva, F., Porcu, L., and Del Barrio-García, S., 2015. Discovering prominent themes of Integrated Marketing Communication research from 1991 to 2012: A co-word analytic approach. International Journal of Advertising, 34(4), 678-701.

Muñoz-Leiva, F., Sánchez-Fernández, J., Liébana-Cabanillas, F.J., and López-Herrera, A.G., 2012. Applying an automatic approach for showing up the hidden themes in financial marketing research (19612010). Expert Systems with Applications. 39(12), 11055-11065. 
Murgado-Armenteros, E. M., Gutiérrez-Salcedo, M., Torres-Ruiz, F. J., and Cobo, M. J., 2015. Analysing the conceptual evolution of qualitative marketing research through science mapping analysis. Scientometrics, 102(1), 519-557.

Ortiz, D., 2020. Marketing y publicidad: ¿cuáles son las diferencias? $C y$ berclick. Retrieved from: https://www.cyberclick.es/numerical-blog/ marketing-y-publicidad-cuales-son-las-diferencias

Phan, K. L., Wager, T., Taylor, S. F., and Liberzon, I., 2002. Functional neuroanatomy of emotion: a meta-analysis of emotion activation studies in PET and fMRI. Neuroimage, 16(2), 331-348.

Pieters, R., and Wedel, M., 2004. Attention capture and transfer in advertising: Brand, pictorial, and text-size effects. Journal of Marketing, 68(2), 36-50.

Pieters, R., and Warlop, L., 1999. Visual attention during brand choice: The impact of time pressure and task motivation. International Journal of Research in Marketing, 16 (1), 1-16.

Pieters, R., Wedel, M., and Van der Lans, R., 2019. Eye tracking methodology for research in consumer Psychology. New York. Routledge.

Pieters, R., Wedel, M., and Rosbergen, E., 1999. Visual attention to repeated print advertising: A test of scanpath theory, Journal of Marketing Research, 36(4), 424-438.

Poole, A., and Ball, L.J., 2006. Eye Tracking in HCI and Usability Research, in Ghaoui, C. (Ed.), Encyclopedia of Human Computer Interaction, IGI Global, Hershey, Pennsylvania (USA).

Pritchard, A., 1969. Statistical Bibliography or Bibliometrics? Journal of Documentation, 25(4), 348-349.

Qiu, S., Hu, J., and Han, T., 2020. Social Glasses: Simulating Interactive Gaze for Visually Impared People in Face-to-Face Communication. International Journal of Human- Computer Interaction, 36(9), 839-855.

Ramírez, A., 2012. Eye-tracking: una técnica de seguimiento de la mirada utilizada en la validación de unidades de aprendizaje. Conference: XIII Encuentro Internacional Virtual Educa Panamá. Retrieved from: https://www.researchgate.net/publication/258878114

Rayner, K., 1998. Eye movements in reading and information processing: 20 years of research. Psychological Bulletin, 124, 372-422. https://doi.org/10.1037/0033-2909.124.3.372

Reisen, N, Hoffrage, U., and Mast, F.W., 2008. Identifying decision strategies in a consumer choice situation. Judgment and Decision Making, 3(8), 641-658.

Reyes, M., 2017. Registro de patrones de lectura con dispositivos de eye tracker de bajo coste y estudio de su aplicación para la recomendación de diagnósticos de patologías. Escuela Politécnica Superior, Madrid.

Rodríguez-López, M.E., Alcántara-Pilar, J.M., Del Barrio-García, S., and Muñoz-Leiva, F., 2020. A review of restaurant research in the last two decades: A bibliometric analysis. International Journal of Hospitality Management, 87, 102387. https://doi.org/10.1016/j.ijhm.2019.102387

Romano-Bergstrom, J., and Schall, A.J., 2014. Eye tracking in user experience design. Elsevier: Waltham, MA (USA).

Rumpf, C., Breuer, C., and Boronczyk, F., 2020. Predicting consumer gaze hits: A simulation model of visual attention to dynamic marketing stimuli. Journal of Business Research, 111, 208-217.

Rytewiki, 2019. Eye Tracking. Copyright. Retrieved from: https:// es.ryte.com/wiki/Eye_Tracking

Sci2s: Soft Computing and Intelligent Information Systems Research Group, 2011. SciMAT (v. 1.0) [Software]. University of Granada, Granada, available online in: http://sci2s.ugr.es/scimat/.

Senju, A., Southgate, V., White, S., and Frith, U., 2009. Mindblind eyes: an absence of spontaneous theory of mind in Asperger syndrome. Science, 325(5942), 883-885.
Senju, A., and Csibra, G., 2008. Gaze following in human infants depends on communicative signals. Current Biology, 18(9), 668-671.

Siegrist, M., Leins-Hess, R., and Keller, C., 2015. Which front-of-pack nutrition label is the most efficient one? The results of an eye-tracker study. Food Quality and Preference, 39, 183-190.

Small, H., 1973. Co-citation in the scientific literature: a new measure of the relationship between two documents. Journal of the American Society for Information Science, 24(4), 265-269.

Stagg, S., Linnell, K.J., and Heaton, P., 2014. Investigating eye movement patterns, language, and social ability in children with autism spectrum disorder. Development and Psychopathology, 26(2), 529-537.

Tazanidou, E., Petre, M., Minocha, S., and Grayson, A., 2005. Combining Eye.Tracking and Conventional Techniques for Indicacitons of User-Adaptability. IFIP Conference on Human, 3585, 753-766.

Teixera, T.S., Wedel, M., and Pieters, R., 2010. Moment-to-moment optimal branding in TV commercials: Preventing avoidance by pulsing. Marketing Science, 29(5), 783-804.

Treistman, J., and Gregg, J.P., 1979. Visual, Verbal and responses to print ads. Journal Of Adverstising Research, 19(4), 41-47.

Van Der Lans, R., Pieters, R., and Wedel, M., 2012. Eye-Movement Analysis of Search Effectiveness. Journal of the American Statistical Association, 103, 452-461.

Van Eck, N. J., and Waltman, L., 2009. How to normalize cooccurrence data? An analysis of some well-known similarity measures. Journal of the American Society for Information Science and Technology, 60(8), 1635-1651.

Viedma-Del-Jesus, M. I., Perakakis, P., Muñoz, M. Á., López-Herrera, A. G., and Vila, J., 2011. Sketching the first 45 years of the journal Psychophysiology (1964-2008): A co-word-based analysis. Psychophysiology, 48(8), 1029-1036.

Waltman, L., 2016. A review of the literature on citation impact indicators. Journal Of Informetrics, 10(2), 365-391.

Wang, Q.Z., Wedel, M., Huang, L.Q., and Lui, X., 2018. Effects of model eye gaze direction on consumer visual processing: Evidence from China and America. Information \& Management, 55(5), 588-597.

Wang, S., Chen, Y., Yuan, Y., Haiyun, Y., and Zheng, S., 2016. Visualizing the Intellectual Structure of Eye Movement Research in Cartography. International Journal of Geo-Information, 5(10), 168, $1-22$.

White, H.D., and McCain, K.W., 1998. Visualizing a discipline: An author co-citation analysis of information science, 1972-1995. Journal of the American Society for Information Science, 49(4), 327-355.

Yang, Y., Wu, M., and Cui, L., 2012. Integration of three visualization methods based on co-word analysis. Scientometrics, 90, 659-673.

Yang, Y., and Wang, C.C., 2015. Trend of Using Eye Tracking Technology in Business Research. Journal of Economics, Business and Management, 3(4), 447-451.

Yan, E., and Ding, Y., 2010. Weighted citation: An indicator of an article's prestige. Journal of the Association for Information Science and Technology, 61, 1635-1643.

Young, E., 1984. Visibility archived by outdoor advertising. Journal of Advertising Research, 24(4), 19-21.

Zeng, L., Zili, L., Zhao, Z., and Mao, M., 2018. Landscapes and Emerging Trends of Virtual Reality in Revent 30 Years; a Bibliometric Analysis. 2018 IEEE Smartworld, 8-12 Oct, 1852-1858.

Zurawicki, L., 2010. Neuromarketing: Exploring the brain of the consumer. Springer Science \& Business Media. 
